\title{
Allocation of visual attention to spatial locations: Tradeoff functions for event-related brain potentials and detection performance
}

\author{
G. R. MANGUN and S. A. HILLYARD \\ University of California, San Diego, La Jolla, California
}

\begin{abstract}
Event-related brain potentials (ERPs) were recorded in response to unilateral arrays of letters flashed in rapid, randomized sequences to left and right visual field locations. Subjects were required to focus attention exclusively on either left or right field stimuli, or to divide attention in different proportions between the two fields, with the aim of detecting infrequent target letters. Both $d^{\prime}$ and percent hits for target detections increased significantly as attentional allocation to a stimulus location increased. Attention operating characteristic (AOC) curves for the target detection scores were highly similar in form to those for the amplitudes of the long-latency, endogenous ERP components-N350-650 and P400-800 (P300). All of these measures showed gradual, nearly rectangular tradeoff functions. In contrast, the AOC curves for the early sensoryevoked components displayed steep, nearly linear amplitude tradeoffs as attention was increasingly allocated to one visual field at the expense of the other. The early and late ERP components were considered as indices of separate but interacting levels of attentional selection having different operating principles.
\end{abstract}

The ability to direct attention voluntarily to selected regions of visual space plays a central role in human perception. When attention is focused on a particular location, stimuli presented at that location can be responded to with greater speed (see, e.g., Eriksen \& Yeh, 1985; Hawkins, Shafto, \& Richardson, 1988; Posner, Snyder, \& Davidson, 1980) and discriminated with greater accuracy (Downing, 1988; Prinzmetal, Presti, \& Posner, 1986). Yet despite the growing evidence that spatial attention influences perceptual processing, considerable controversy exists concerning the mechanisms that underlie the facilitated performance observed to occur with spatial attention. It has been argued, for example, that changes in decision and response bias factors rather than enhanced perceptual processing mediate the performance benefits of spatial attention (e.g., Müller \& Findlay, 1987; Müller \& Rabbitt, 1989; Shaw, 1984; Sperling, 1984).

Mechanisms of visual selective attention have also been studied extensively, using physiological measures of sensory and perceptual processing. In particular, eventrelated brain potentials (ERPs) provide measures of the transmission of sensory information through successive levels of the afferent pathways and cortical receiving areas. ERP studies of visual-spatial attention in humans

This research was supported by grants from NIMH (MH-25594) and NINCDS (NS-17778) and ONR Contract N00014-86-K-0291 to S. A. Hillyard. G. R. Mangun was supported by NIMH Research Service Award I F31 MH09360. We thank M. Kutas, T. H. Bullock, J. C. Hansen, H. J. Heinze, R. Ohst, K. S. Mangun, and C. Montejano for assistance, advice, and/or encouragement. Correspondence may be addressed to G. R. Mangun, Department of Psychiatry, Pike House, Dartmouth Medical School, Hanover, NH 03756, or to S. A. Hillyard, Department of Neurosciences, M-008, University of California, San Diego, La Jolla, CA 92093. have identified attention-related amplitude modulations of the early, sensory-evoked $\mathrm{P} 1$ and $\mathrm{N} 1$ peaks as well as longer latency ERP components related to selective stimulus processing (Eason, 1981; Eason, Harter, \& White, 1969; Harter, Aine, \& Schroeder, 1982; Hillyard \& Münte, 1984; Mangun, Hansen, \& Hillyard, 1987; Mangun \& Hillyard, 1987, 1988; Neville \& Lawson, 1987; Rugg, Milner, Lines, \& Phalp, 1987; Van Voorhis \& Hillyard, 1977).

The manner in which attention alters the ERPs provides information about the neural processes that mediate spatial attention. Typically, the attended-location stimuli evoke P1 (latency of $90-130 \mathrm{msec}$ ) and N1 (160-190 msec) peaks of greater amplitude. This pattern of $\mathrm{Pl}$ and $\mathrm{N} 1$ enhancement is unique to visual-spatial attention, and it is not seen during selective attention to other stimulus features such as color or shape. For the P1 component in particular, the amplitude modulations during spatial attention usually occur with little or no change in component waveshape, latency, or scalp distribution (Hillyard \& Mangun, 1987; Mangun \& Hillyard, 1987, 1988, 1990). Such findings have been interpreted as evidence for a process of selective sensory gating, or "gain control," in the visual pathways during spatial attention (Eason, 1981; Hillyard \& Mangun, 1987).

A mechanism of selective sensory gain control should result in greater amounts of perceptual information reaching higher centers from attended than from unattended locations. Accordingly, attention-related increases in ERP amplitude should, under appropriate conditions, be associated with enhanced detection and discrimination performance. Such a relationship is suggested by concomitant increases in early ERP amplitudes (P1 and/or N1) and 
measures of perceptual discriminability that have been observed when attention is focused on one stimulus location rather than divided between two locations (Eason, 1981; Kramer, Sirevaag, \& Hughes, 1988; Van Voorhis \& Hillyard, 1977). In addition, a positive relationship between P1 and N1 amplitudes and target detection accuracy was observed when the distance between the focus of attention and the location of the target stimuli were varied; with increasing separation, ERP amplitudes and $d^{\prime}$ scores dropped off together (Mangun \& Hillyard, 1988). Despite these initial observations, the detailed relationships among attentional allocation, ERP amplitudes, and measures of visual perception remain poorly understood.

In the study described here, we aimed to define more precisely the perceptual significance of ERP amplitude modulations during spatial attention. Our approach was to vary systematically the relative allocation of attention between competing stimuli at right and left visual field locations and to examine the covariation between ERP amplitudes and measures of target discrimination (see, e.g., Kinchla, 1980; Sperling, 1984). With such an approach, the properties of the underlying attentional processes indexed by various ERP components can be clarified and the extent to which attention-related ERP variations are predictive of perceptual accuracy can be determined. Previous ERP studies of attentional allocation between competing tasks have demonstrated that the amplitude of the P300 (P3) wave reflects the allocation of attention during dual-task performance (Hoffman, Houck, MacMillan, Simons, \& Oatman, 1985; Isreal, Wickens, Chesney, \& Donchin, 1980; Kramer \& Strayer, 1987, 1988; Wickens, Kramer, Vanasse, \& Donchin, 1983). In addition, studies in which shorter latency ERP components have been investigated in either divided attention paradigms (Parasuraman, 1985) or dual-task designs (Kramer et al., 1988) have provided evidence that the auditory and visual N1 components vary in amplitude as the relative priority of competing tasks is manipulated.

The present design followed the methods of Kinchla (1980) and Sperling (1984); subjects were instructed to vary in a stepwise fashion the proportion of total attention paid to arrays of letters flashed to the left and right visual fields, with the task being to detect occasional target letters. Attentional allocation was varied from $100 \%$ focused left, through three divided attention conditions (left/right: $75 \% / 25 \%, 50 \% / 50 \%, 25 \% / 75 \%$ ), to $100 \%$ focused right. Thus, the covariation between ERPs and target-detection performance could be measured as a function of the relative attentional deployment between the spatially separate stimulus displays. The use of three divided attention conditions permitted changes in attentional deployment to be investigated independently of possible confounds due to concurrence costs (Navon \& Gopher, 1979) or differential task strategies during focused versus divided attention (Herdman \& Friedman, 1985; Parasuraman, 1985; Wickens, 1984).

A major goal of this study was to define the quantitative relationship between ERP amplitude and discrimina- tion accuracy for the early, sensory-evoked components (P1 and N1) versus the later, endogenous waves (e.g., P300) as attentional allocation was varied. It was expected that both types of ERPs should covary with measures of perceptual discrimination, since the early attention effects appear to reflect a sensory gain control process (see above) and the later waves (especially P300) have been shown to relate closely with performance accuracy and discrimination confidence in a variety of task situations (e.g., Donchin, Karis, Bashore, Coles, \& Gratton, 1986; Hillyard \& Picton, 1987; Pritchard, 1981). However, the form of the covariation may well differ for these two classes of physiological measures that purportedly index early sensory transmission and higher decision/classification processes, respectively.

Analyses of the present data will include the construction of attention operating characteristic (AOC) curves, which plot performance (or ERP amplitude) for one task as a function of performance (or ERPs) for a second, concurrently performed task (Bonnel, Possamai, \& Schmitt, 1987; Kinchla, 1980; Hoffman et al., 1985; Norman \& Bobrow, 1975; Parasuraman, 1985; Sperling, 1984; Wickens, 1980, 1984). This type of analysis helps to portray the quantitative tradeoff in the performance and ERP measures as attention is systematically varied between two competing tasks or input channels (in this case between the left and right stimulus arrays). The form of the AOC function indicates, among other things, the degree of competition between the two tasks for available attentional "resources" (see, e.g., Navon \& Gopher, 1979; Norman \& Bobrow, 1975; Wickens, 1980, 1984). Through comparison of the AOC curves for indices of target-detection performance with those of sensory-evoked versus endogenous ERPs, the perceptual mechanisms indexed by the different classes of ERP components may be clarified.

\section{EXPERIMENT 1}

\section{Method}

Subjects. Sixteen healthy right-handed persons (10 males) between the ages of 18 and 30 participated as paid volunteers. All had normal or corrected-to-normal vision.

Stimuli. Arrays of letters were flashed for $100 \mathrm{msec}$, one array at a time, in random order to left and right visual field locations. Each array contained four uppercase letters (taken from the set E, F, T) arranged in a semicircle with a radius of $3^{\circ}$. The arrays were centered on the horizontal meridian, intersecting it $3^{\circ}$ lateral to a central fixation point; each of the equally spaced letters was $0.7^{\circ}$ tall and $0.5^{\circ}$ wide. Eight different combinations of Es and Fs were used as nontarget stimulus arrays, and eight different combinations of Es, Fs, and Ts were used as target arrays; only one $T$ was present in a target array and was equally likely to occur at any of the four letter positions. Target probability was 0.20 in a randomized sequence. The interstimulus intervals of the flashed arrays varied at random between 300 and $450 \mathrm{msec}$ (rectangular distribution). The stimuli were presented in white on black, on a video monitor under computer control.

Procedure. During testing, the subjects reclined in a comfortable chair in an electromagnetically shielded recording chamber. Prior to and for the duration of each $1.5 \mathrm{~min}$ run, the subjects were required to maintain fixation on a central point on the video screen. 
After eye fixation was verified (see below), the subjects were instructed either to direct attention (but not their eyes) exclusively to the left ( $100 \%$ left $/ 0 \%$ right) or right ( $0 \%$ left $100 \%$ right) stimulus arrays, or to divide attention between the two sides in specified proportions. The three divided attention conditions were: $75 \%$ left $/ 25 \%$ right, $50 \%$ left $/ 50 \%$ right, and $25 \%$ left $/ 75 \%$ right.

The task was to detect and respond to the infrequent target arrays (those with $T s$ in any of the four letter positions) in the designated visual field(s), pressing a right-hand button for right visual field targets and a left-hand button for left field targets. The subjects were instructed that they were to respond quickly and accurately. Buttonpresses were classified as hits or false alarms: Hits were defined as the first response in the time window from 200 to $1,200 \mathrm{msec}$ following the occurrence of a target at the designated location. Subsequent responses in this time window not attributable to a succeeding target, as well as responses outside this window, were designated as false alarms. The subjects were asked to maintain a continuous state of left/right attentional allocation throughout the entire run during the divided conditions, rather than to divide the proportion of time spent attending left or right.

Following a practice session of 5 to 15 runs, 6 runs each of the five attention conditions were presented, which yielded approximately 500 nontarget trials and 125 target trials per averaged ERP waveform following artifact rejection. The order of runs was counterbalanced both within and across subjects. Rest periods of 1-2 min were given between each run, with longer rest periods provided after each 10 runs or as needed.

The critical importance of maintaining eye position on the central fixation point was made clear to the subjects. Prior to receiving the instructions for each run, the subjects were required to fixate the central point, and then, on command, to deviate their gaze to a point $10^{\circ}$ left of fixation, then to a point $10^{\circ}$ right of fixation, and then back to the central point. Once eye position was assured with this procedure, the subject was instructed how to allocate attention on that run and the run was initiated. In addition to the rejection criteria described in the following section, runs were discarded and later repeated if deviations of eye position were observed in the electro-oculogram (EOG).

Recording. Scalp potentials were recorded using $\mathrm{Ag}-\mathrm{AgCl}$ electrodes attached with collodion at F3, F4, C3, C4, O1, and $\mathrm{O} 2$ of the International 10-20 System of electrode placement. In addition, electrodes were placed at eight nonstandard sites: parietal sites included PL and PR (located half the distance from Pz to the ear canal), and $\mathrm{P} 1$ and $\mathrm{P} 2$ (located $10 \%$ of the interaural distance lateral from $\mathrm{Pz}$ ). Additional posterior scalp sites included the occipital $\mathrm{OL}$ and OR sites (located halfway between $\mathrm{O} 1$ and $\mathrm{T} 5$, and $\mathrm{O} 2$ and $\mathrm{T} 6$, respectively), and the parieto-occipital sites $1 \mathrm{pO}$ and $2 \mathrm{pO}$ (located halfway between $\mathrm{O} 1$ and $\mathrm{P} 1$, and $\mathrm{O} 2$ and $\mathrm{P} 2$, respectively). Eye blinks and vertical deviations of fixation were recorded with an electrode located below the right eye, and the horizontal EOG was recorded between electrodes located at the outer ocular canthi. With the exception of the horizontal EOG electrodes, which were referenced to each other, all other electrodes were referred to an electrode located at the right mastoid process.

The EEG and EOG channels were amplified with a bandpass of $.01-100 \mathrm{~Hz}$ (half amplitude low- and high-frequency cutoffs), digitized on-line at a rate of 250 samples per second, and recorded on magnetic tape. ERPs were computed off-line, using a program that averaged overlapping epochs of raw EEG beginning $200 \mathrm{msec}$ before each stimulus and continuing for $800 \mathrm{msec}$ after stimulus onset. Separate averages were computed for left and right visual field targets and nontargets for each of the five attention conditions. Artifact rejection was performed before averaging to reject trials contaminated with blinks or eye movements, excessive muscular activity, or amplifier blocking. ${ }^{1}$ These types of artifacts vary in size among normal individuals, and thus, peak-to-peak amplitude values for rejection of blinks, eye movements, and muscle activity were determined for each subject on the basis of visual inspection of the subject's EEG and EOG traces; a computer program used these values to remove contaminated epochs of EEG.

Data analysis. Mean amplitude and peak amplitude measures of the unfiltered ERP components were obtained relative to the mean voltage of the 100 -msec prestimulus baseline, using computer algorithms. In general, peak measures were taken for components occurring prior to about $300 \mathrm{msec}$, while mean amplitude measures were obtained for the broader, long-latency waves. The latency windows for the measures were centered approximately on the peak latencies of the ERPs seen in the grand average waveforms $(N=$ 16); see Table 1 for specific latency windows used. These measurement windows were the same for all subjects and were selected so that each ERP deflection was measured in each subject.

Peak latencies were obtained, using a computer program that identified the maximum voltage of a given polarity within a specified latency range. Latency windows for measurement were determined as for the peak amplitude measures. ERP components were labeled according to a polarity-latency convention, so that, for example, the positive P1 and negative N1 peaks over the occipital scalp were designated $\mathrm{P} 110$ and $\mathrm{N} 180$, respectively. The latency designation for each peak was the mean latency of the peak in the attended waveform collapsed across left and right stimuli and the four electrodes in a given region (see below), rounded to the nearest $5 \mathrm{msec}$. ERP components whose waveforms spanned hundreds of milliseconds were labeled to indicate their particular latency range; thus, for example, the P300 was designated P400-800.

Table 1

F Ratios and Significance Levels of ANOVA Comparisons for ERP Amplitudes to Left and Right Field Nontarget Stimuli in Experiment 1 (Geiser-Greenhouse Corrected)

\begin{tabular}{|c|c|c|c|c|c|c|}
\hline \multirow[b]{2}{*}{ Component } & \multirow[b]{2}{*}{ Window } & \multicolumn{2}{|c|}{$\begin{array}{c}\text { Attention } \\
\text { Main Effects* }\end{array}$} & \multicolumn{3}{|c|}{ Interactions $\dagger$} \\
\hline & & $F$ ratio & $p$ & $A \times B$ & $B \times C$ & $B \times C \times D$ \\
\hline Occ. P110 & $80-140$ & 11.0 & $<.001$ & $<.001$ & $<.001$ & $<.05$ \\
\hline Occ. N180 & $140-220$ & 9.2 & $<.001$ & $\mathbf{n} . \mathbf{s}$ & $<.01$ & $<.001$ \\
\hline Par. N165 & $140-220$ & 8.4 & $<.001$ & n.s. & $<.01$ & n.s. \\
\hline Ant. N145 & $100-200$ & 8.5 & $<.01$ & n.s. & $<.05$ & $<.001$ \\
\hline Occ. N295 & $240-340$ & 8.2 & $<.01$ & n.s. & $<.01$ & n.s. \\
\hline Ant. $P 200-400$ & $200-400$ & 6.9 & $<.05$ & n.s. & $<.05$ & n.s. \\
\hline Occ. N350-650 & $350-650$ & 13.3 & $<.01$ & $<.05$ & $<.05$ & n.s. \\
\hline Par. N350-650 & $400-650$ & 5.2 & $<.05$ & n.s. & $<.05$ & n.s. \\
\hline
\end{tabular}

*Main effect of attention is Factor $B$. †Interactions are presented for ANOVA with factors of: $A=$ visual field of stimulation (left vs. right), $B=$ attention condition (attend $100 \%, 75 \%, 50 \%$, $25 \%$, or $0 \%$ ), $C=$ hemisphere of recordings (contralateral vs. ipsilateral), and $D=$ electrode pair (see Method section). 
ERP amplitude differences as a function of attention condition, visual field of stimulation, or recording site were analyzed, using repeated measures analyses of variance (ANOVA) separately for each ERP component. Separate ANOVAs were performed for ERPs recorded from anterior (F3/F4, C3/C4), parietal (P1/P2, PL/PR), and occipital (O1/O2, OL/OR) electrode locations, since the ERPs obtained from these regions differed in component latency and morphology. Factors in the overall ANOVAs were: $A=$ visual field of stimulus (left vs. right), $B=$ attention condition (attend $100 \%$, $75 \%, 50 \%, 25 \%$, or $0 \%$ ) $C=$ hemisphere of recording (contralateral vs. ipsilateral to field of stimulus), $D=$ electrode pair (e.g., F3/F4 vs. C3/C4), and $E=$ subjects. ${ }^{2}$ Geisser-Greenhouse corrections were employed to reduce the positive bias resulting from repeated factors with greater than two levels (e.g., Factor B) (Jennings \& Wood, 1976).

Calculations of $d^{\prime}$, percent hits, and beta for target detections were made on the basis of hit and false alarm rates separately for left and right field targets following the method of Hansen and Hillyard (1980). Repeated measures ANOVAs were used to compare differences in $d^{\prime}$, beta, percent hits, and reaction times among the attention conditions.

\section{Results}

Discrimination performance. Figure 1 summarizes the changes in the behavioral measures as a function of attentional allocation. The target-detection scores, $d^{\prime}$, and percent hits varied systematically as a function of attention, being higher for conditions with greater attentional allocation $[F(3,45)=32.2, p<.001$, and $F(3,45)=$ $164.6, p<.001$, for $d^{\prime}$ and percent hits, respectively].
RTs also varied with attention, being fastest for the $100 \%$ focused conditions and slowing as attention was increasingly allocated to the opposite field stimuli $[F(3,45)=$ $135.2, p<.001]$. Similar patterns were observed for beta scores, which were significantly $[F(3,45)=33.6, p<$ $.001]$ higher for the lower levels of attentional allocation. No significant differences were observed in RT, $d^{\prime}$ scores, percent hits, or beta values between left and right visual field stimuli.

ERPs to nontarget stimuli. Grand average ERPs over the 16 subjects to the nontarget stimuli are shown in Figure 2. Overlapped recordings are shown from the frontal, central, parietal, and occipital scalp regions during three of the five conditions of attentional allocation. ${ }^{3} \mathrm{Be}$ tween 0 and $200 \mathrm{msec}$ in latency, the ERPs were characterized by the P110 (P1) and N180 (N1) peaks over the contralateral occipital scalp, together with a parietal N165 peak and an anterior N145 wave. Significant modulations of the occipital P110 $[F(4,60)=11.0, p<.001]$ and $\mathrm{N} 180[F(4,60)=9.2, p<.001]$ waves were evident as a function of attentional allocation (Table 1). Significant attention effects were also observed for the anterior $\mathrm{N} 145[F(4,60)=8.5, p<.01]$ and the parietal N165 $[(F(4,60)=8.4, p<.001]$ peaks. In general, each of these peaks was larger when a higher proportion of the subjects' attention was allocated to the evoking stimulus arrays (Figure 3).
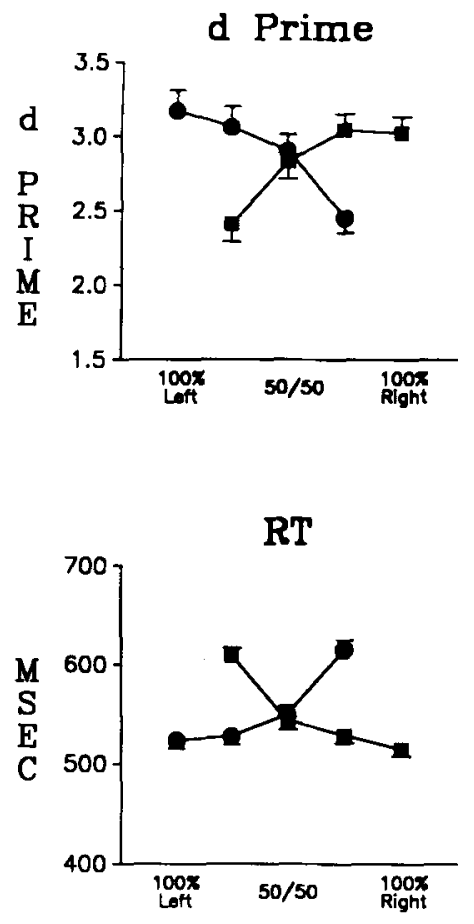

ATTENTIONAL ALLOCATION
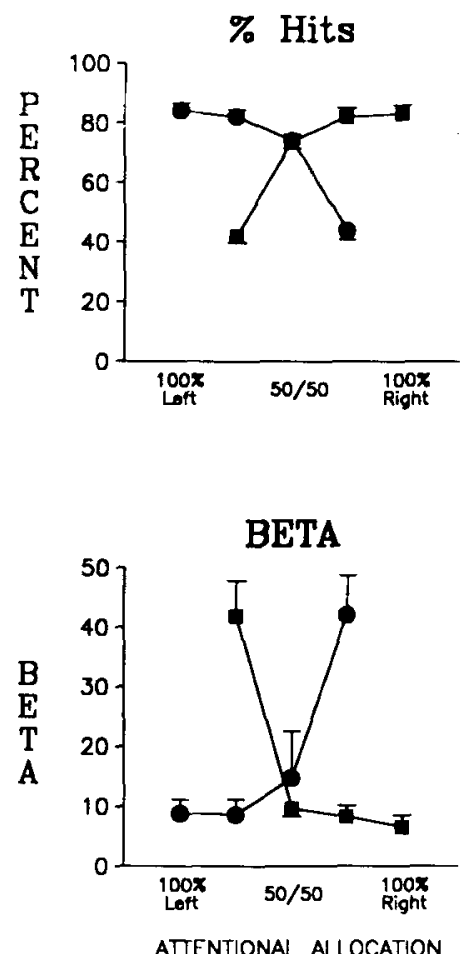

Figure 1. Graphs of performance measures as function of attentional allocation. On the abscissa are indicated the allocations, going from $100 \%$ left $(0 \%$ right) through the divided attention conditions to $100 \%$ right ( $0 \%$ left). Note that the $75 \%$ left $/ 25 \%$ right and $25 \%$ left $/ 75 \%$ right conditions are plotted but not labeled on the abscissa. 


\section{Right Standards}
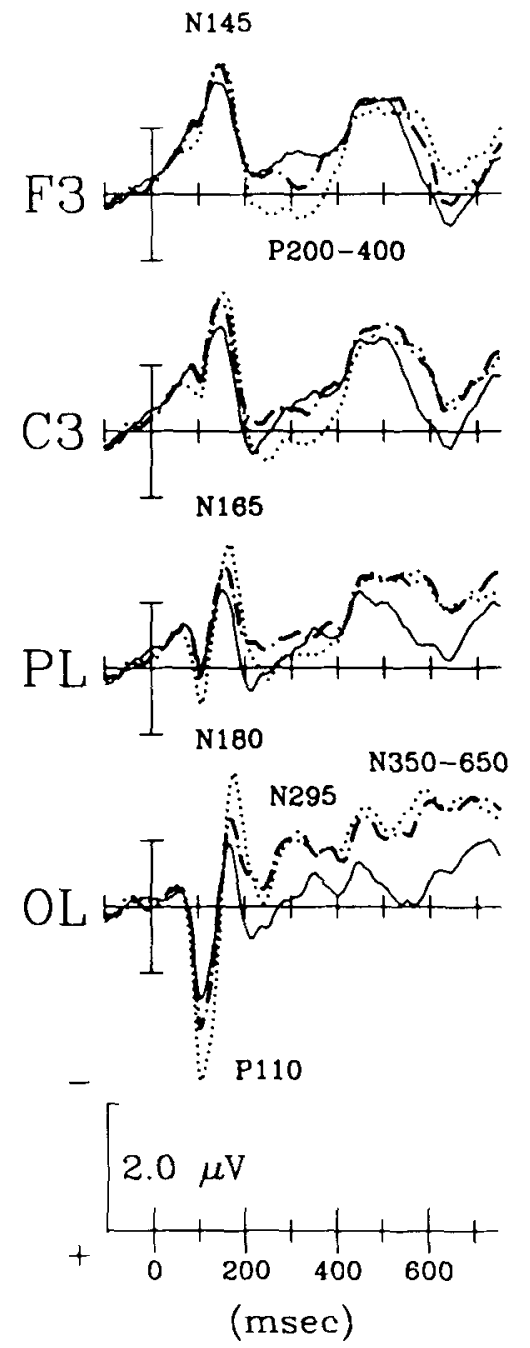

\section{Left Standards}
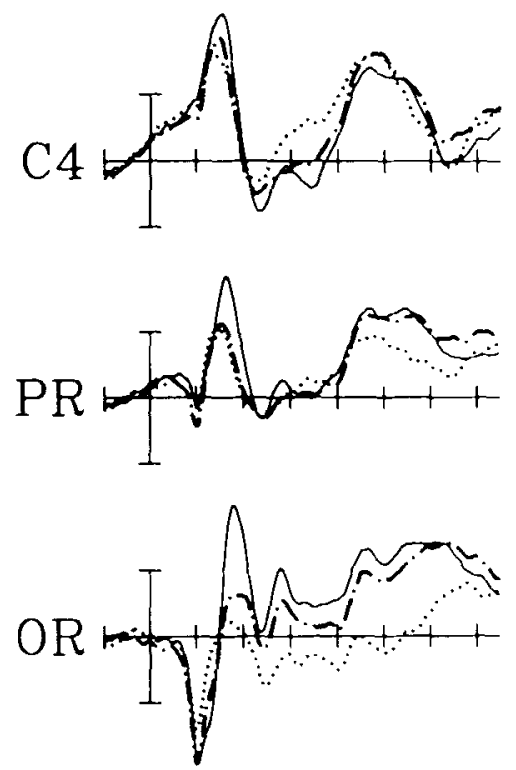

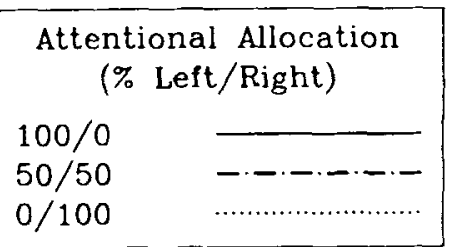

Figure 2. Grand average ERPs $(N=16)$ to nontarget stimuli presented to the left and right visual fields under three of the five attentional allocation conditions. ERPs are superimposed for conditions when attention was focused $100 \%$ to the left (solid), or $100 \%$ to the right (left 0\%; dotted), or divided $50 \%$ left $/ 50 \%$ right (dot-dash). Recordings shown are from contralateral scalp sites over left and right frontal (F3 and F4), central (C3 and C4), parietal (PL and PR), and occipital (OL and OR) areas.

The attention effect on the early occipital P110 (and N180) peak was manifest as a progressive modulation of its amplitude as a function of attentional allocation, with no appreciable changes in latency (onset $80-90 \mathrm{msec}$; peak $112 \mathrm{msec}$ ) or waveshape (see Figure 2). The P110 was largest over scalp sites contralateral to the visual field of the stimulus $[F(1,15)=26.3, p<.001$, for main effect of contralateral vs. ipsilateral hemisphere]. In addition, the effect of attention on the P110 component was also significantly contralateral $[F(4,60)=7.06, p<$ .001 , for attention $\times$ hemisphere interaction], and it was larger for right visual field stimuli $[F(4,60)=6.69, p<$ .001 , for attention $\times$ visual field of stimulus interaction].
Like the P110, the occipital N180, parietal N165, and anterior N145 peaks were also laterally asymmetrical, being largest and more modulated by attention over the contralateral scalp (Table 1).

Isopotential contour maps were constructed to assess the distribution of voltages over the scalp at the peak of the P110 component (112 msec) during different conditions of attention (Figure 4). The results indicate that the scalp localization of the P110 focus did not change as its amplitude was modulated by changes of attentional allocation. The attention-difference maps in Figure 4 (right) show that the location of the scalp maxima for the attention effect on P110 corresponded to the focus of the P110 
P 110

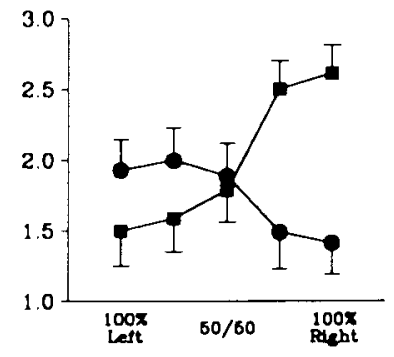

M

1

C

$\mathrm{R}$

$\mathrm{O}$

$\checkmark$

$\mathrm{O}$

$\mathrm{L}$
$\mathrm{S}$
N295

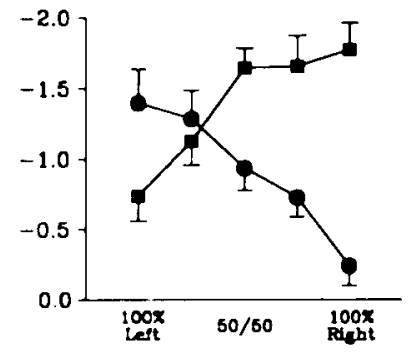

N350-650

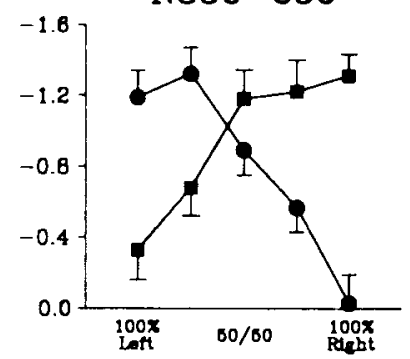

N180

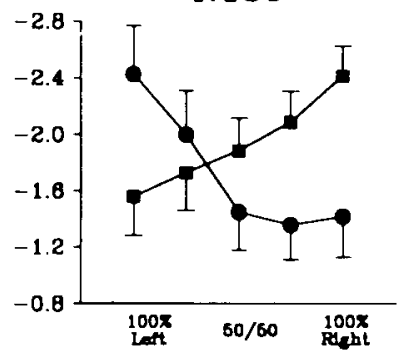

$\mathrm{P} 200-400$

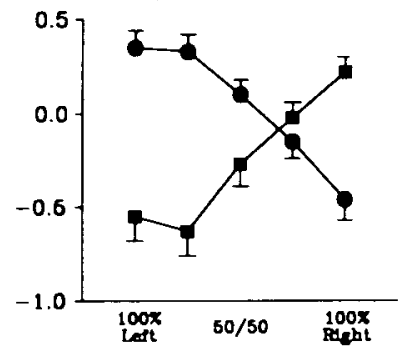

P400-800

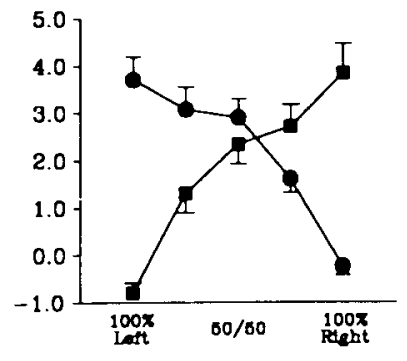

ATTENTIONAL ALLOCATION

Figure 3. ERP measures plotted as a function of attentional allocation. Values are means ( $\pm S E$ ) across the 16 subjects of the P110, N180, and N295 peaks, and mean amplitude measures of the $\mathrm{P200}-400, \mathrm{N350}-650$, and $\mathrm{P} 400-800$ (P300) components in microvolts. The P200-400 values were recorded from frontal scalp sites, and the P400-800 (to targets) values were recorded from pO sites; the remaining ERP amplitudes are to nontarget stimuli recorded from the occipital scalp. Note that the ordinate for ERP components varies according to whether the component was positive or negative in polarity. Thus, upwards in each plot indicates the increasing size of a deflection from zero, whether of increasing negative or positive amplitude.

peak itself (i.e., at the lateral occipital scalp sites $\mathrm{OL}$ and OR for the right and left visual field flashes, respectively).

The attention-related components beyond $200 \mathrm{msec}$ in latency were generally broader in form, and they were not clearly evident in the unattended waveforms (Figure 2); thus, they most likely represent endogenous attentionrelated activity. Anteriorly, a broad P200-400 wave was significantly larger during the $100 \%$ focused condition and dropped off progressively in amplitude as attention was divided between the two visual fields $[F(4,60)=6.9, p<$ $.05]$. Over the posterior scalp, a small N295 peak was found to be significantly larger during higher allocation conditions $[F(4,60)=8.2, p<.01]$. A broad, posterior negative N350-650 wave was also found to be significantly larger during $100 \%$ focused attention, with its amplitude decreasing at lower attentional allocations $[F(4,60)$ $=13.3, p<.01$, occipitally]. As was the case for the earlier ERP peaks, a contralateral pattern was seen for the attention effects on the later occipital N295 peak and the broad N350-650 wave. The anterior P200-400 wave, however, was slightly larger ipsilaterally.

ERPs to target stimuli. The effects of attention on the early peaks of the ERP for targets were very similar to those for nontargets. Significant attention-related modu- 
Attend
$100 \%$ Left
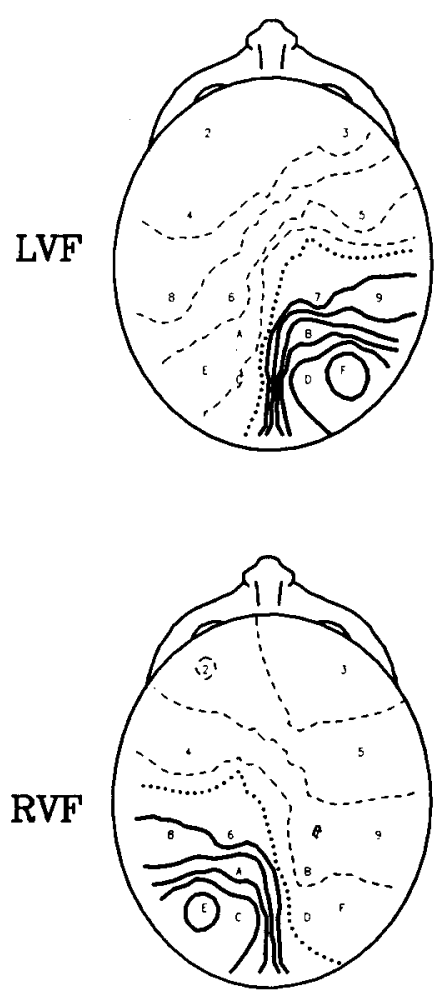

Attend

$50 \% / 50 \%$
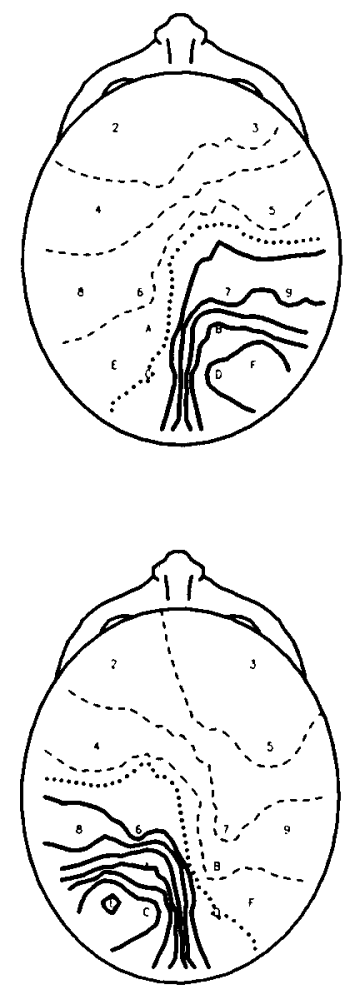

Attend $100 \%$ Right
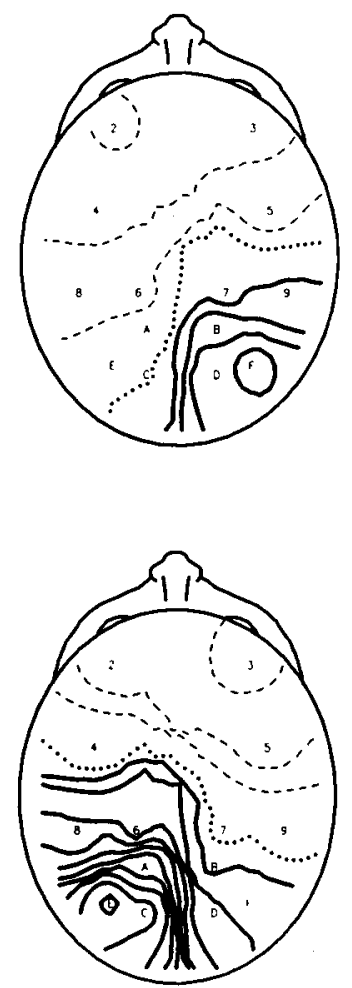

Difference Map $100 \%-0 \%$

Figure 4. Isopotentials contour maps showing the scalp topography of the P110 component (at 112-msec latency) in response to left (top row) and right (bottom row) stimuli during attend $100 \%$ left $(0 \%$ right), $50 \%$ left $/ 50 \%$ right, and $100 \%$ right (0\% left) conditions. The scalp amplitude maximum of the P110 is over the right lateral occipital scalp for left stimuli, and over the left lateral occipital scalp for right stimuli. The locations of these P110 maxima did not change as a function of the attentional allocation condition; only their amplitudes were modulated. The maps at the far right are the attentional difference maps formed by subtracting the attend $0 \%$ maps from the attend $100 \%$ maps. Dotted line $=0.0 \mathrm{~V}$, solid lines are positive values, and broken lines are negative voltage values; voltage increments $=0.27 \mu \mathrm{V}$ for each line traversed.

lations were observed for the occipital P110 and N180 peaks as well as the N295 wave. Anteriorly, only the P200-400 was significantly enlarged with attention. The pattern of lateral asymmetry which characterized the ERPs to nontargets was also seen for the peaks in the target waveforms.

The most prominent component elicited by target stimuli was a late positive wave (P3 or $\mathrm{P} 300$ component), which peaked at approximately $565 \mathrm{msec}$ and was largest at the parieto-occipital (1pO and 2pO) sites. Figure 5 shows grand average ERPs to target stimuli with a time base and gain appropriate for viewing the $\mathrm{P} 300$, here termed $P 400-800$. The $P 400-800$ was significantly greater in amplitude during $100 \%$ focused conditions and decreased in amplitude as attention was allocated to the opposite visual field (Figure 3). This was true whether one considered the parieto-occipital $\mathrm{P} 400-800$ to all targets $[F(4,60)=$ $38.9, p<.001]$ or only targets that were correctly detected $[F(3,45)=4.9, p<.02]$. The $\mathrm{P} 400-800$ wave did not differ in amplitude between contralateral and ipsilateral scalp sites when all targets (hits and misses) were considered. However, for correctly detected targets, the P400-800 was largest ipsilaterally with respect to the side of the stimulus [main effect of hemisphere; $F(1,15)=$ $33.5, p<.001]$.

ERP-Performance correlations. Linear regression was performed to investigate the relationship between target detectability and ERP amplitudes between subjects; that is, did subjects with higher detection scores have larger ERPs? Regressions for $d^{\prime}$, percent hits, and RT versus the amplitude of the attention sensitive ERP components were done separately for left and right visual field stimuli and each attention condition. In general, significant correlations were not obtained, although some small between-subject correlations were found for the $d^{\prime}$ measure versus the N350-650 to nontargets. ${ }^{4}$

Correlations based on difference scores were also calculated. The change in target-detection scores between 


\section{Right Targets Left Targets}

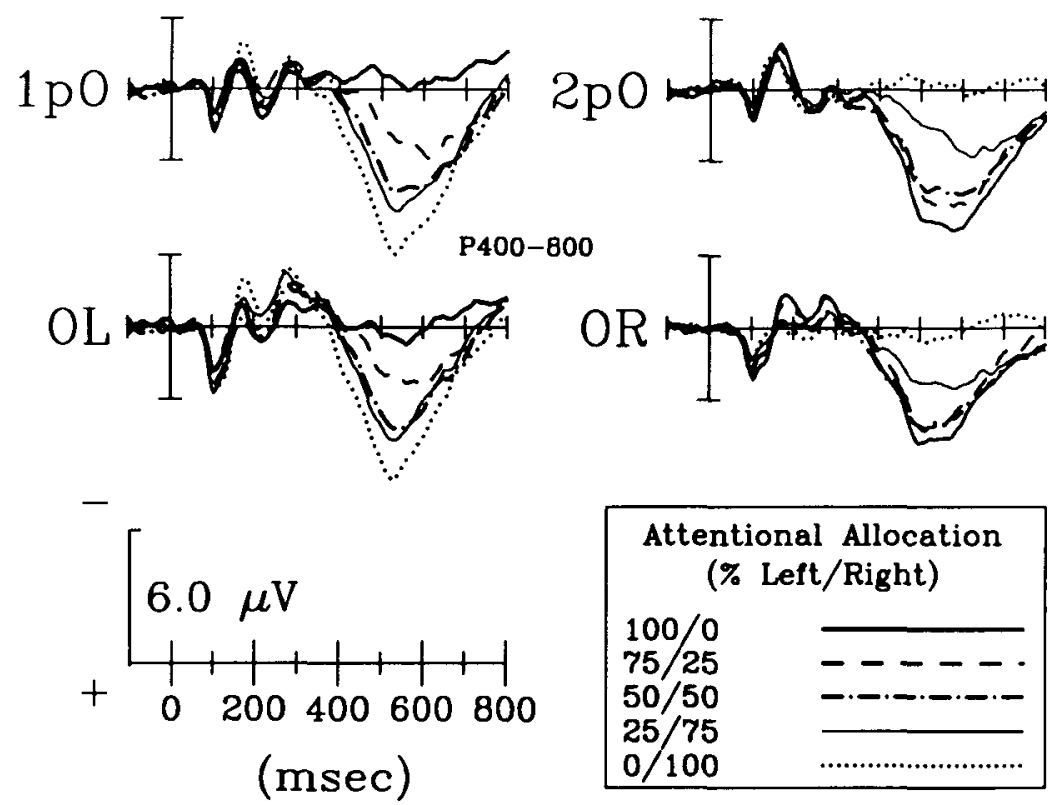

Figure 5. Grand average ERPs to left and right visual field target stimuli recorded from scalp sites contralateral to the stimulus in Experiment 1. Recording sites are left and right parieto-occipital (1pO/2pO) and lateral occipital (OL/OR) electrodes.

two different allocation conditions was regressed with respect to the corresponding change in ERP amplitude; this correlation enabled the examination of whether or not subjects who increased their performance levels by a relatively large amount as attentional allocation increased also showed a similarly large increase in ERP amplitude. These difference scores were calculated for the left and right stimuli for the following conditions: $75 \%$ versus $50 \%$ conditions, $75 \%$ versus $25 \%$ conditions, and $50 \%$ versus $25 \%$ conditions. In general, the correlation coefficients were small and did not reach statistical significance.

There was, however, a generally positive relationship between performance and ERP amplitudes. Regression of the group mean detection scores over the four conditions $(100 \%$ to $25 \%$ ) with respect to the group mean P400-800 amplitudes revealed a significant linear relationship $[r=.77, F(1,6)=8.7, p<.03]$. This correlation did not reach significance for either the P1 $10[r=.66$, $F(1,6)=4.7, p>.07]$ or the $\mathrm{N} 180[r=.65, F(1,6)=$ $4.3, p>.081$ peak.

AOC curves. Figure 6 shows AOC curves for performance scores ( $d^{\prime}$, percent hits, and RT), and Figure 7 shows AOC plots for ERP amplitudes as attention was shifted from $100 \%$ left through the various divided attention conditions to $100 \%$ right. The performance scores or ERP amplitudes obtained in the $100 \%$ focused condition are plotted on the axes. The vertical and horizontal dotted lines drawn through these points intersect at the “independence point" of the AOC plot, which indicates the values that would be obtained if divided attention scores were equivalent to those obtained during focused attention.

The AOC curves for $d^{\prime}$, percent hits, and RT measures display gradual tradeoffs with changes in attentional allocation. The curves are relatively far from the origin of the plot, and the $50 \% / 50 \%$ point tends toward the independence point, giving the curves a rectangular appearance, especially for RT and percent hits. The $d^{\prime}$ curve is also far from the origin and tends to bow outward toward the independence point, though to a lesser extent than the other performance AOC curves.

The AOC curves for the various ERP components displayed two types of tradeoff functions (Figure 7). The shorter latency occipital P110 and N180 peaks and parietal N165 and central N145 peaks showed steep declines in amplitude in response to a stimulus in one field as increasing amounts of attention were allocated to the opposite field stimulus. Thus, these curves lay closer to the origin of the plots and were more or less linear in form. In contrast, the AOC curves for the longer latency N350-650 and P400-800 components displayed relatively more gradual tradeoff functions, resulting in a more rectangular form that was similar to those observed for the performance measures.

To assess the linearity of the various $A O C$ curves for the ERP measures, linear regression analyses were performed, using the five pairs of points defining each AOC curve. Significant linear correlations were revealed for 


\section{PERFORMANCE}
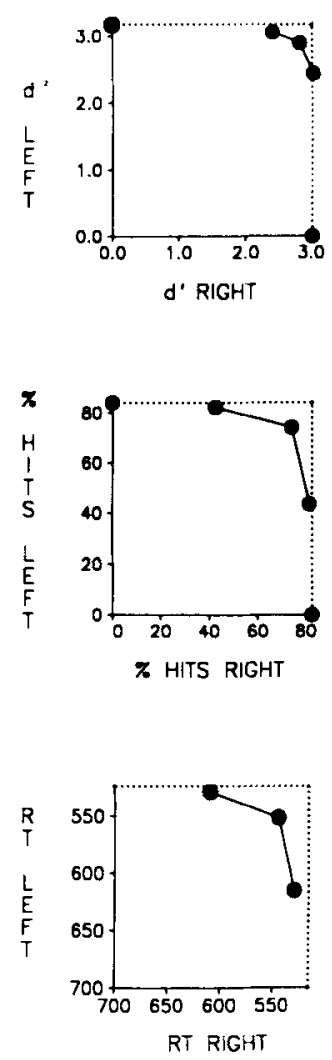

Figure 6. Attention operating characteristic (AOC) curves plot the performance measures for left field stimuli as a function of right field stimuli. These curves depict the tradeoff in performance as attention is shifted from $100 \%$ to left stimuli, through the intervening divided attention conditions, to $100 \%$ to right stimuli. Performance during the $100 \%$ focused attention conditions is plotted on the axes, and the point of intersection of the vertical and horizontal dotted lines drawn at these values defines the "independence point." This point indicates the locus at which divided attention performance would be as high as that during focused attention conditions.

the $\mathrm{P} 110(r=-.99, p<.001), \mathrm{N} 180(r=-.91, p<$ $.05), \mathrm{N} 165(r=-.93, p<.05), \mathrm{N} 145(r=-.89, p<$ $.05)$, and $\mathrm{P} 200-400(r=-.99, p<.001)$ components. In contrast, correlations performed for the AOC curves for N350-650 $(r=-.74)$ and $\mathrm{P} 400-800(r=-.86$ for all targets; $r=-.75$ for target hits) components did not reach significance, indicative of their departure from linearity.

\section{Discussion}

The attention-related changes in the sensory-evoked occipital P110 peak were manifest as amplitude modulations with no observed changes in the waveshape, latency, or scalp distribution of this peak. Such a pattern of ERP amplitude modulation is consistent with a mechanism of early sensory gating (Eason, 1981; Hillyard \& Münte, 1984), whereby spatial attention acts as a gain control mechanism over the information flowing in the visual pathways. Since the contralateral occipital scalp focus of P110 is con- sistent with a generator in lateral extrastriate cortex, it seems reasonable to propose that the changes in $\mathrm{P} 110$ reflect the modulatory influence of descending neural projections on either visual cortical neurons or the subcortical visual pathways (Eason, 1981; Harter \& Aine, 1984; Hillyard \& Mangun, 1987). These findings in humans may reflect mechanisms similar to those underlying the changes in single-unit activity in monkey prestriate visual cortex during spatial attention (see, e.g., Moran \& Desimone, 1985; Mountcastle, Motter, Steinmetz, \& Sestokas, 1987; Spitzer, Desimone, \& Moran, 1988).

In contrast to the amplitude modulations of the exogenous $\mathrm{P} 110$ and N165/180 peaks, the longer latency $\mathrm{P} 200-400, \mathrm{~N} 295$, and N350-650 waves to nontargets and the P400-800 to targets appeared to reflect the activity of endogenous neural systems selectively brought into play to process attended stimuli. The N295 and N350-650 are probably manifestations of the selection negativity described by Harter and associates, and others, which is elicited during attention to a variety of stimulus features
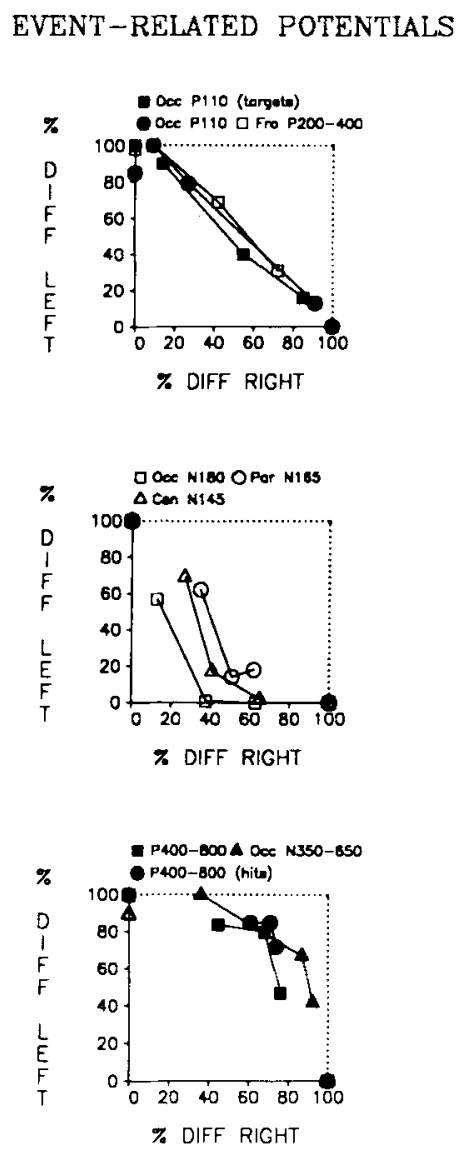

Figure 7. AOC curves plot the ERP amplitudes for left stimuli as a function of right stimuli. ERP values are normalized as percentages of the difference between the maximum amplitude (set to $100 \%$ ) and the minimum amplitude (set to $0 \%$ ) values for that component. The labels "Occ P110" and "Occ P110 (targets)" refer to standard (nontarget) and target P110 measures, respectively. 
such as color, orientation, or location, as well as to conjunctions of these features (Harter \& Previc, 1978; Harter et al., 1982; Hillyard \& Münte, 1984; Mangun \& Hillyard, 1987; Previc \& Harter, 1982; Wijers, G. Mulder, Okita, L. J. M. Mulder, \& Scheffers, 1989). The anterior P200-400 component may be related to the late frontal positivity (250-500 msec) elicited by attended-location stimuli that was described by Hillyard and Münte (1984). However, this frontal positivity may only be elicited under particular stimulus/task parameters, since in several related studies of spatial selective attention such an effect has not been observed (e.g., Hillyard, Simpson, Woods, Van Voorhis, \& Münte, 1984; Mangun \& Hillyard, 1987, 1988; Rugg et al., 1987). The P400-800 wave to targets is clearly an example of the P300 component that is associated with the detection of unpredictable, task-relevant stimuli in a wide range of situations (Donchin et al., 1986; Hillyard \& Picton, 1987; Pritchard, 1981).

The present tradeoffs in amplitude of the ERPs with attention are in line with previous studies reporting changes in P300 and/or N1 during dual-task performance (e.g., Hoffman et al., 1985; Isreal et al., 1980; Kramer et al., 1988; Parasuraman, 1985; Wickens et al., 1983). In general, ERP amplitudes and measures of target-detection speed and accuracy displayed similar changes with attentional allocation; as attention was progressively allocated to stimuli at a given visual field location, ERP amplitudes and detection accuracy for those stimuli increased. The present findings also accord with the results of previous studies of spatial attention, in which decrements in ERP amplitudes and performance were found when attention was divided between two visual field locations rather than focused on one (Eason, 1981; Van Voorhis \& Hillyard, 1977). Furthermore, since processing priority was manipulated across three levels during divided attention, the possible confounds of concurrence cost, differential focused/ divided strategies, or nonspecific effects (e.g., Navon \& Gopher, 1979) were more effectively controlled than they have been in studies in which only focused and divided attention were compared.

The AOC curves display the tradeoffs in ERPs and performance with changing attentional allocation to the left and right visual field stimuli. The AOC curves for the early occipital components P110 and $\mathrm{N} 180$ and also for the more anterior N165, N145, and P200-400 waves showed steep amplitude tradeoffs with changes in attentional allocation. AOC curves such as these have been described as "linearly limited" and result from the dependent measure's varying linearly with resource allocation for both tasks (Norman \& Bobrow, 1975). Interestingly, the tradeoffs for the N180, N165, and N145 components were even steeper than those observed for the occipital P110 peak (Figure 7, top vs. middle panels). The AOC curves for these negative peaks both tended toward the origin of the plot, suggesting a pattern of interference during conditions of divided attention for the processes indexed by N180 as well as N165 and N145 (Navon \&
Gopher, 1979). The differences between the AOC curves for the occipital P110 and N180 may relate to evidence that the posterior $\mathrm{Pl}$ and $\mathrm{N} 1$ components of the visual ERP index functionally independent processes, as is indicated by dissociations between the two in recent studies (e.g., Heinze, Luck, Mangun, \& Hillyard, in press).

In sharp contrast, the longer latency N350-650 and P400-800 waves did not fall off so steeply in amplitude as attention was withdrawn from a location; substantial amplitude decrements were only observed between the $50 \%$ and $25 \%$, as well as the $25 \%$ and $0 \%$, allocation conditions. Thus, a clear dichotomy was obtained in the tradeoff functions of the early (e.g., P110 and N180) versus late (e.g., P400-800) ERP components.

The AOC curves plotted for the performance measures also indicated a more gradual tradeoff function as attention was withdrawn from one visual field and allocated to the other. This was evident for the RT and percent hits AOC plots, and it may also be true for the $d^{\prime}$ curve. Thus, the forms of the AOC curves for the later ERP components and for the performance measures were similar, tending toward a more rectangular shape, while the sensory-evoked ERP components took a distinctly different, more linear form.

Despite the overall positive relationships observed between ERP and performance measures, ERP amplitudes did not significantly correlate with the behavioral measures of target-detection accuracy between subjects. Thus, subjects who showed large changes in ERP amplitudes between attention conditions did not necessarily show large changes in performance. There was, however, a positive relationship between ERPs and performance scores that led to a significant correlation between group mean performance scores and group mean P400-800 amplitude; the early sensory-evoked components did not reach significance in this comparison. Such a result may stem, in part, from the differences in the sensitivity of the early versus late ERP components and performance to attentional allocation.

\section{EXPERIMENT 2}

Our primary purpose in this experiment was to replicate the ERP attention effects of Experiment 1 while providing additional control of the subject's eye fixation. When carefully monitored, the horizontal electro-oculogram can assure that eye fixation is maintained with an accuracy of only about $1.0^{\circ}$ at best. Since the early sensory-evoked ERPs are sensitive to changes in stimulus parameters such as retinal eccentricity, deviations of eye fixation toward or away from a lateralized stimulus might possibly produce ERP modulations similar to those observed in Experiment 1. Given that the results of Experiment 1 include an interesting dichotomy between the early and late ERP components as a function of attentional allocation, it was important to establish that eye movements did not contribute to those differences. To provide greater control over this possible artifact, we employed a sensitive infra- 
red eye-monitoring device to assure that eye fixation was maintained. In addition, the stimuli were located farther out in the lateral visual fields in Experiment 2, so that the effects of small shifts of fixation on the visual ERPs would also be minimized.

\section{Method}

The method was the same as in Experiment 1, except as noted.

Subjects. Eight healthy right-handed persons ( 6 males) between the ages of 18 and 35 participated as paid volunteers. All had normal or corrected-to-normal vision.

Stimuli. Arrays of letters were flashed, one array at a time, in random order to the left or right upper visual field quadrants. Each array contained four uppercase letters (taken from the set $E, F, T$, and $H$ ), arranged in arcs so that each letter was $6.2^{\circ}$ from fixation. The letters were $0.6^{\circ}$ tall and $0.3^{\circ}$ wide. Random combinations of Es, Fs, and Ts were used as nontarget stimulus arrays, and arrays containing an $\mathbf{H}$ were used as target stimuli. The interstimulus intervals of the flashed arrays varied at random between 250 and $550 \mathrm{msec}$ (rectangular distribution). The white letter stimuli were flashed on a continuously present black vertically oriented rectangle $\left(4.3^{\circ} \times 3.6^{\circ}\right)$ located in the upper visual field quadrant with its medial border $4.5^{\circ}$ lateral to the vertical meridian and its lower border on the horizontal meridian; the background field was dimly illuminated in red.
Procedure. Prior to and during each 40-sec run, the subjects were required to maintain fixation on a central point on the video screen. After fixation was obtained, the instruction was given to direct attention exclusively to either the left $(100 \%$ left $/ 0 \%$ right) or the right $(0 \%$ left $/ 100 \%$ right) stimulus arrays, or to divide attention equally between the two sides $(50 \%$ left/ $50 \%$ right).

During each run, the subjects were required to detect and respond to the infrequent target arrays (those with $\mathrm{Hs}$ in any of the four letter positions) in the appropriate visual field(s), again pressing with the ipsilateral hand. Following a practice session of 5 to 15 runs, 10 runs each of the three attention conditions were presented, yielding approximately 378 nontarget trials and 72 target trials per averaged ERP waveform following artifact rejection.

Recording. Scalp potentials were recorded, using tin electrodes mounted in an electrode cap. Electrodes were located at F3, F4, C3, C4, P3, P4, T5, T6, O1, and O2 of the International 10-20 System. Additional scalp sites included the occipital $O L$ and $O R$ sites and an electrode over the left mastoid process. With the exception of the horizontal EOG electrodes, all other electrodes were referred to the right mastoid process. ERPs were subsequently algebraically re-referenced to obtain an averaged mastoid reference.

Fixation assurance. Ocular fixation was verified, using a commercially available monitoring system (Applied Science Laboratories, Model 210) mounted on spectacle frames worn by the subjects. For horizontal movements, an infrared light illuminated the surface of the left eye at the iris-scleral border. Eye movements

\section{Left Standards}
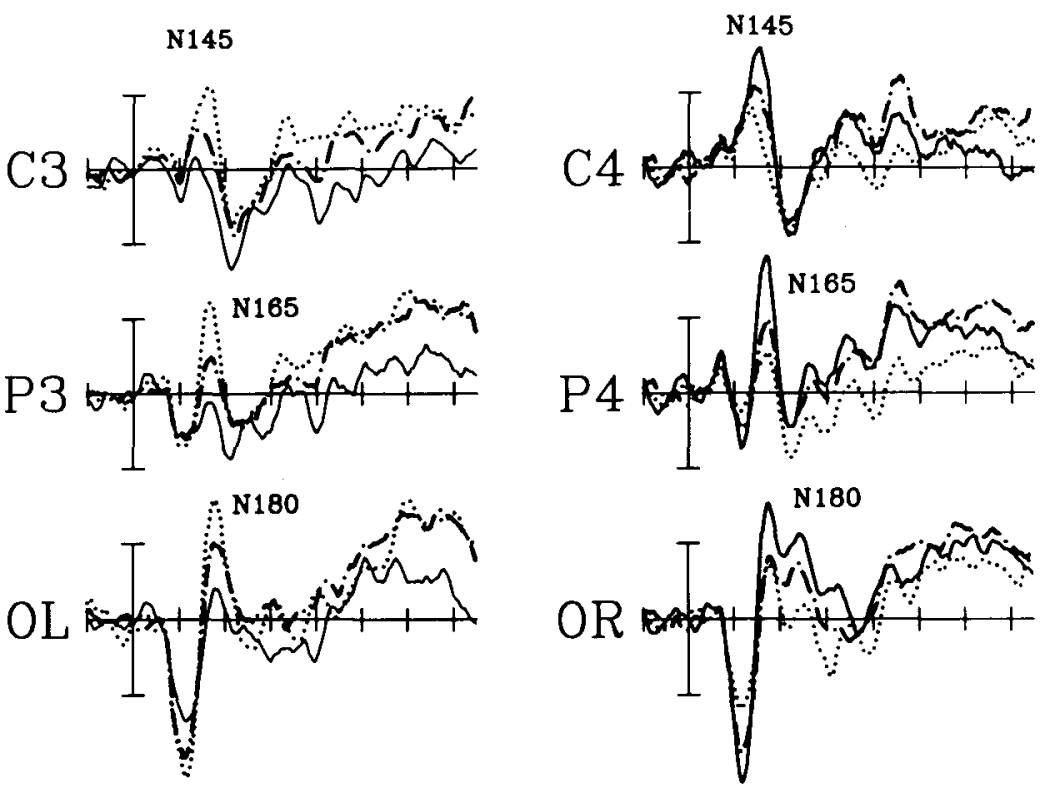

P110

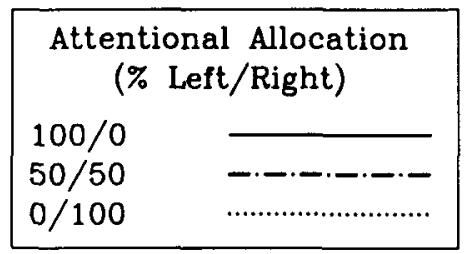

P110

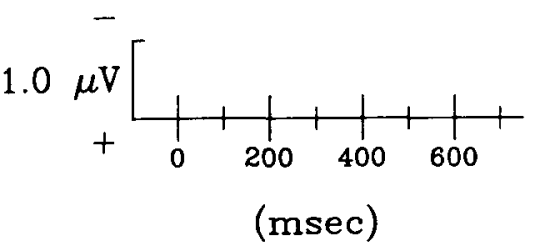

Figure 8. Grand average ERPs to left and right visual field nontarget stimuli, recorded from contralateral scalp locations in Experiment $2(N=8)$. Overlapped are the ERPs when the subjects devoted attention $100 \%$ left $/ 0 \%$ right (solid), $50 \%$ left $/ 50 \%$ right (dot-dash), and $0 \%$ left $/ 100 \%$ right (dotted). 


\section{Right Targets Left Targets}

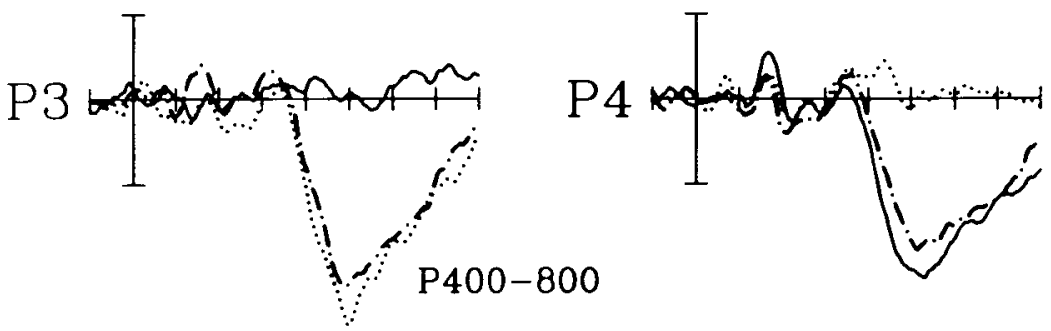

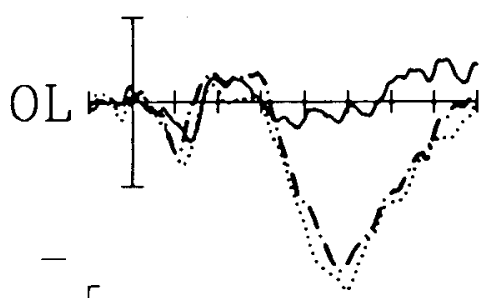
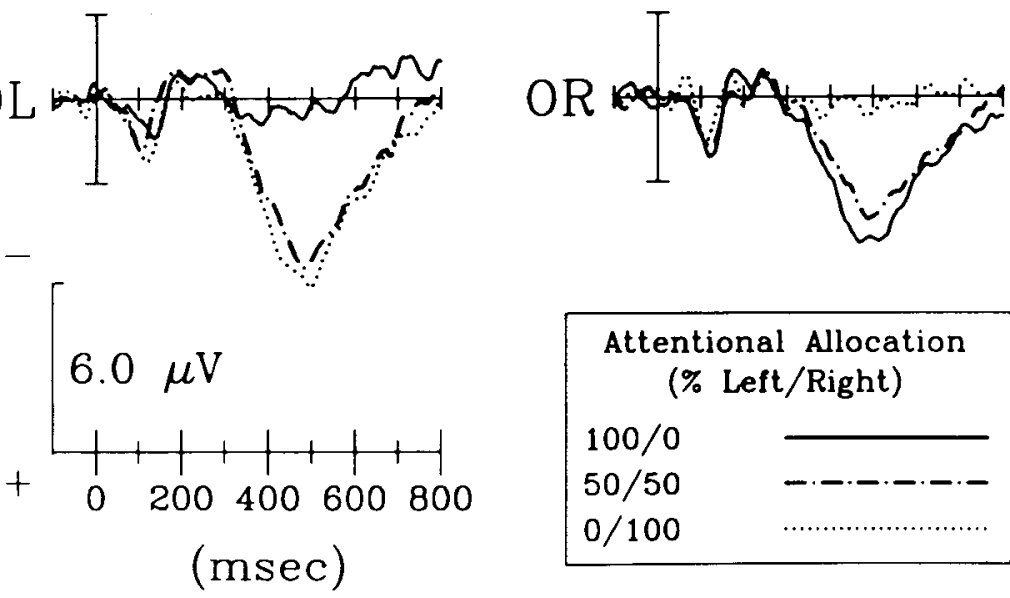

Attentional Allocation

(\% Left/Right)

$100 / 0$

$50 / 50$

$0 / 100$

Figure 9. Grand average ERPs to left and right visual field target stimuli, recorded from contralateral parietal and occipital scalp sites. Prominent is the P400-800 (P300) component visible over central (not shown), parietal, and occipital scalp sites. The P400-800 is largest when attention is $100 \%$ focused, and slightly reduced in amplitude when attention is divided between the two visual fields.

produce systematic changes in the amount of reflected and recorded infrared light that can be related to eye position. Horizontal eye position information was displayed to the investigators on a video monitor, and the horizontal signal was also digitized and stored on magnetic tape. Movements of the head were minimized with a rigid chin support and headrest.

To calibrate the eye monitor, the subjects were instructed to fixate designated locations on the video screen and the infrared device was calibrated so that eye movements of $0.25^{\circ}-0.50^{\circ}$ could be easily detected. Prior to the initiation of each run and before the attention instructions were given for that run, the subjects were told to fixate the central fixation point, the infrared device was adjusted, and the attentional instruction was delivered. Each run was scored for maintenance of fixation and was discarded or repeated if deviations from fixation occurred. Thus, the data presented here are to be considered as free from deviations of eye position within the limits of resolution of the infrared device as used (approx. $0.25^{\circ}-0.50^{\circ}$ ).

\section{Results}

Discrimination performance. As in Experiment 1, $d^{\prime}$ and RT measures varied as a function of attentional allocation. The $d^{\prime}$ scores were significantly higher for the $100 \%$ than for the $50 \%$ allocation conditions [3.34 vs. $3.14 ; F(1,7)=5.7, p<.05]$. RTs were also faster for $100 \%$ focused attention, slowing as attention was divided between the two visual fields $(517$ vs. $536 \mathrm{msec} ; F(1,7)=$
$6.0, p<.05]$. Neither the percent hits scores [84.7 vs. $79.9 ; F(1,7)=4.7, p>.06]$ nor the beta scores $[7.4$ vs. $10.4 ; F(1,7)=2.5, p>.10$ ] were significantly different as a function of focused versus divided attention.

Event-related potentials. Grand average ERPs over 8 subjects to the left and right visual field nontarget stimuli are shown in Figure 8. ERPs to target stimuli are shown in Figure 9.

As in Experiment 1, the ERPs displayed the prominent occipital P110 and N180, parietal N165, and anterior N145 peaks. These peaks were significantly larger when higher percentages of the subjects' attention were allocated to the stimuli (Table 2). ERPs to target stimuli exhibited the prominent P400-800 (P300) component when subjects focused their attention on the target location or divided their attention between left and right locations; no P400-800 was elicited when subjects ignored the target location.

Similarly to the findings of Experiment 1, the P110 and N180 components showed steep tradeoffs when attention was divided between two locations rather than focused on one. These decrements were quite substantial-a $37 \%$ amplitude reduction for $\mathrm{P} 110$ and an average $64 \%$ reduction for the N180, N165, and N145 components. In con- 
Table 2

F Ratios and Significance Levels of ANOVA Comparisons for ERP Amplitudes to Left and Right Field Nontarget Stimuli in Experiment 2 (Geiser-Greenhouse Corrected)

\begin{tabular}{|c|c|c|c|c|c|c|}
\hline \multirow[b]{2}{*}{ Component } & \multirow[b]{2}{*}{ Window } & \multicolumn{2}{|c|}{$\begin{array}{c}\text { Attention } \\
\text { Main Effects* }\end{array}$} & \multicolumn{3}{|c|}{ Interactions $\dagger$} \\
\hline & & $F$ ratio & $p$ & $A \times B$ & $B \times C$ & $B \times C \times D$ \\
\hline Occ. P110 & $80-140$ & 15.9 & $<.001$ & n.s. & n.s. & n.s. \\
\hline Occ. N180 & $140-220$ & 5.5 & $<.05$ & n.s. & n.s. & $<.05$ \\
\hline Par./Tem. N165 & $140-220$ & 15.3 & $<.001$ & n.s. & n.s. & n.s. \\
\hline Ant. N145 & $100-200$ & 18.0 & $<.001$ & n.s. & n.s. & n.s. \\
\hline Occ. N295 & $240-340$ & 7.8 & $<.05$ & n.s. & n.s. & n.s. \\
\hline Ant. P200-400 & $200-400$ & 1.6 & n.s. & n.s. & n.s. & n.s. \\
\hline Occ. N350-650 & $350-650$ & 1.8 & n.s. & n.s. & n.s. & n.s. \\
\hline Par. N400-650 & $400-650$ & 1.8 & n.s. & n.s. & n.s. & n.s. \\
\hline
\end{tabular}

* Main effect of attention is Factor $B$. †Interactions are presented for ANOVA with factors of: $A=$ visual field of stimulation (left vs. right), $B=$ attention condition (attend $100 \%, 50 \%$, or $0 \%$ ), $C=$ hemisphere of recordings (contralateral vs. ipsilateral), and $D=$ electrode pair. Separate ANOVAs were performed for ERPs recorded from anterior (F3/F4, C3/C4), parieto-temporal (P3/P4, T5/T6), and occipital (O1/O2, OL/OR) scalp regions.

trast, compared to the focused condition, divided attention reduced the $\mathrm{P} 400-800$ by only $19 \%$, and reduced $d^{\prime}$ and percent hits by a mere $6 \%$ (Figure 10 ).

Neither the anterior P200-400 wave nor the parietal/ occipital N350-650 measures revealed significant amplitude differences with attention (Table 2). Nor did an anterior negative difference visible between 350 and $650 \mathrm{msec}$ at the anterior sites (Figure 8).

\section{Discussion}

The results of Experiment 2 replicate the main behavioral and ERP attention effects of Experiment 1, this time with the fixation of the eyes sensitively monitored. As in Experiment 1, the tradeoffs between 100\% and 50\% allocation conditions in the amplitudes of the sensoryevoked occipital P110 and N180, parietal N165, and anterior N145 peaks were quite steep, whereas the tradeoffs in $\mathrm{P} 400-800, d^{\prime}$, and percent hits over this comparison were very small. Most of the effects of attention on the latter measures were observed between the $50 \%$ and $0 \%$ allocation conditions. The infrared device allowed eye fixation to be assured with an accuracy of $0.25^{\circ}-0.50^{\circ}$ of visual angle, and thus, the significant amplitude modulations of the early sensory-evoked components with changes in attentional allocations are unlikely to have been the result of changes in ocular fixation in either Experiment 1 or Experiment 2.

In contrast to what was found in Experiment 1, no attention effects were obtained over the anterior scalp in the 200-400 msec range (P200-400 of Experiment 1) or in the 350-650 msec time range over the posterior scalp (N350-650 of Experiment 1). Although it is remotely possible that the failure to obtain these longer latency effects resulted from greater control over ocular fixation, a more likely explanation results from changes in the stimulus parameters between the two experiments. The latter interpretation is to be favored, since the effects on the occipital P110 and N180, parietal N165, and anterior N145 peaks, as well as on the P400-800 wave, are virtually identical for Experiments 1 and 2.
The differences in the tradeoffs for the P110 versus the early negative peaks (N180, N165, and N145) were highly similar to those obtained in Experiment 1 (compare Figures 7 and 10). The occipital N180, parietal $\mathrm{N} 165$, and anterior N145 peaks showed very sharp tradeoffs with divisions of attention, suggesting a strong interference effect during divided attention. The P110 showed a more linear pattern, as was observed in Experiment 1. Thus, it appears that this difference between the tradeoff functions of P110 versus N180, N165, and N145 is reliable and may signal differences in their functional properties during spatial attention. Studies that have resulted in differences between the behavior of the P1 and that of the $\mathrm{N} 1$ peaks as a function of spatial attention have also tended to differentiate the frontal and occipital N1 components (e.g., Heinze et al., in press). Thus, it is also of interest that the tradeoff functions were similar for the occipital N180 and the anterior N145 waves in the present experiments.

\section{EXPERIMENT 3}

The findings of Experiment 2 reinforce the finding that the AOC curves for the early and late components differ markedly, with the latter resembling the AOC curves for target discriminability. However, unlike the ERP measures, which provide indices of information processing in the absence of overt behavioral responses, no performance measures could be obtained during the $0 \% / 100 \%$ attention condition for the unattended visual field in either Experiment 1 or Experiment 2. Hence, it may be questionable to assume that target detectability was exactly zero during the $0 \% / 100 \%$ condition, since it was not actually measured for the unattended arrays. If detectability was in fact greater than zero during $0 \%$ allocation, this would affect the rectangularity of the AOC curves. ${ }^{5}$

If only the three divided attention points are considered for Experiment 1, the performance AOC curves display a form that is close to rectangular. This is evident for the percent hits and RT curves, but the $d^{\prime}$ curve is more 


\section{PERFORMANCE}
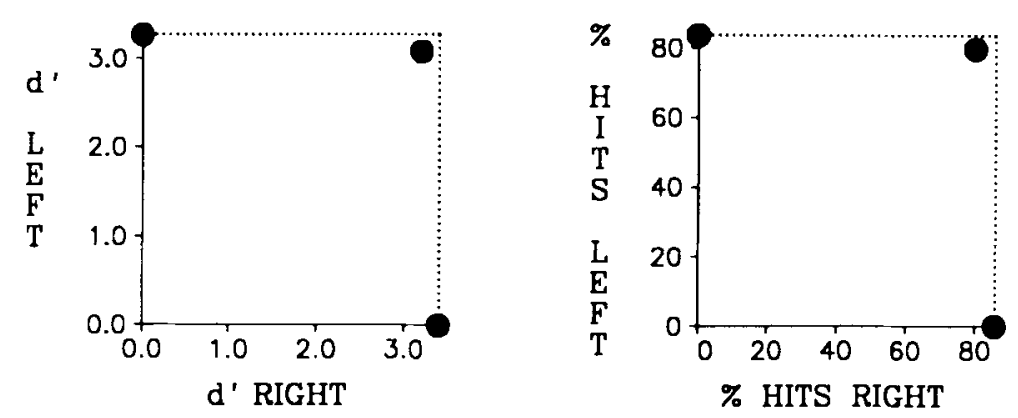

\section{EVENT-RELATED POTENTIALS}
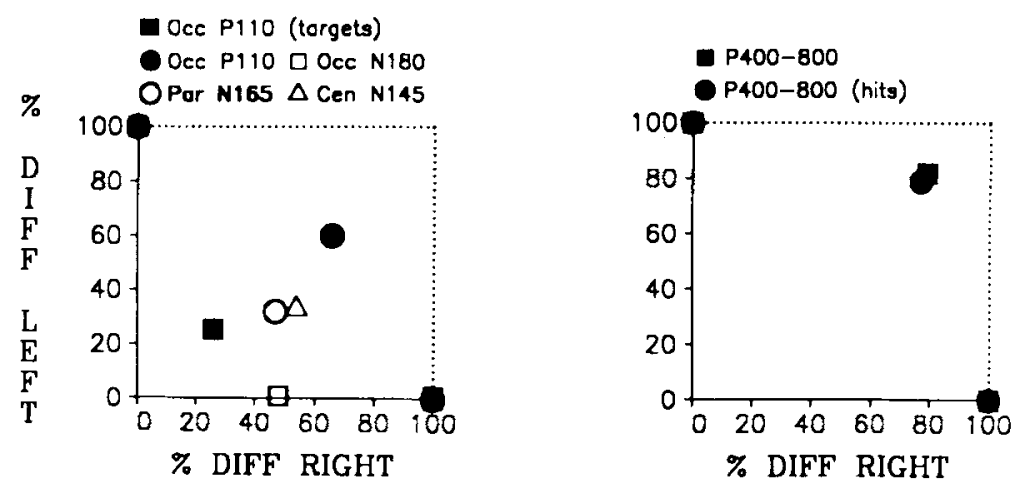

Figure 10. Amplitude values of the performance measures (top) and ERP amplitudes (bottom) for Experiment 2, plotted in format similar to that of data from Experiment 1 shown in Figures 6 and 7. ERP values are normalized as described in Figure 7.

difficult to interpret, due to the close proximity of the divided attention points to each other. The $50 \% / 50 \%$ condition point does tend towards the independence point of the plot, but to characterize the $d^{\prime}$ function as rectangular may be an overstatement.

Whether the AOC curve for $d^{\prime}$ in Experiment 1 is best characterized as rectangular or as linear depends, in part, on the true location of the $100 \% / 0 \%$ points on the curve. To the extent that they lie closer to the axes of the plot, the AOC curve would be best described as rectangular in form. On the other hand, if they lie nearer to, or on top of the points for the $75 \% / 25 \%$ conditions, the linearity or rectangularity of the plot would be more difficult to assess. Perhaps in the $100 \% / 0 \%$ condition the subjects were detecting targets in the unattended location but did not respond because they were instructed not to do so.

One way to determine the actual form of the AOC curve for $d^{\prime}$ is to get a better estimate of unattended channel performance when attention is focused on one location. We obtained such an estimate in the present behavioral control experiment, in which subjects allocated attention between the left and right displays in three different proportions: $95 \% / 5 \%, 50 \% / 50 \%$, and $5 \% / 95 \%$. If the $100 \% / 0 \%$ points of the performance AOC curves of Experiment 1 were similar to the $75 \% / 25 \%$ points, then the $95 \% / 5 \%$ points of the present experiment should also lie near those points. However, if the $95 \% / 5 \%$ condition resulted in AOC points lying significantly closer to the axes of the plot, this would imply that the $100 \% / 0 \%$ condition of Experiment 1 also lay nearer to the axes, thus resulting in a rectangular AOC curve.

\section{Method}

Subjects. Ten healthy right-handed university students ( 9 females) between the ages of 18 and 35 participated as paid volunteers. All had normal vision.

Stimuli and Procedure. The stimuli and procedures were the same as those in Experiment 1, except that: (1) Run length was shortened to $40 \mathrm{msec}$ as in Experiment 2; (2) a total of about 300 nontarget and 75 target trials was obtained; and (3) left/right attentional allocation was varied in three conditions of $95 \% / 5 \%$, $50 \% / 50 \%$, and $5 \% / 95 \%$.

Data recording and analyses. Behavioral data were obtained as in Experiment 1, and eye fixation control was performed as in Experiment 2 . Statistical analyses of $d^{\prime}$, percent hits, RT, and beta measures were performed, using an ANOVA to compare pairs of 
attention conditions with factors of $A=$ visual field (left vs. right), $B=$ attention condition (attend $95 \%$ vs. $50 \%$, or, in a separate ANOVA, $50 \%$ vs. $5 \%$ ), and $C=$ subjects.

\section{Results}

As in Experiments 1 and 2, changes in the behavioral measures were obtained as a function of attentional allocation. Four of the 10 subjects did not, however, respond at all to the stimuli when instructed to allocate $5 \%$ attention to that side. Thus, for the calculation of $d^{\prime}$ scores, these 4 subjects were not included in the analyses, although their results are presented for comparison. In general, for the remaining 6 subjects ( 4 females), $d^{\prime}$, percent hits, RTs, and beta scores were not significantly different between the $95 \%$ and $50 \%$ allocation conditions, but there were highly significant performance decrements between the $50 \%$ and $5 \%$ allocation conditions. Significance levels for the latter comparison for $d^{\prime}$, percent hits, and RTs were $p<.01, p<.001$, and $p<.01$, respectively.

AOC curves for the performance measures for the 6 subjects included in the statistical analyses and for all 10 subjects are plotted in Figure 11. These AOC curves are quite rectangular in form, due to the fact that when $5 \%$ attention was allocated to a lateral stimulus, the performance scores were quite low, dropping to $43 \%$ of their $50 \% / 50 \%$ allocation value for $d^{\prime}$ and $23 \%$ for percent hits.

\section{Discussion}

When subjects were asked to devote $5 \%$ attention to one visual field and $95 \%$ to the other, detection accuracy was well below that obtained in the $75 \% / 25 \%$ condition of Experiment 1. Thus, the results of this behavioral control experiment suggest that in the present task, AOC curves depicting the tradeoff in target detectability are rectangular in form. We presume that in Experiment 1 the $d^{\prime}$ scores in the unattended channel for the $100 \% / 0 \%$ condition would have been at least as close to the axes of the plot as the points generated in the present $95 \% / 5 \%$ condition; thus, the AOC curve for $d^{\prime}$ in Experiment 1 was more rectangular than linear in form. This reinforces the conclusion that the AOC curves for target discrimination are similar in form to those for the long-latency endogenous ERPs in Experiment 1.

One way of quantifying the differences among $A O C$ curves is to calculate the distance of a given curve from the

\section{Subjects}
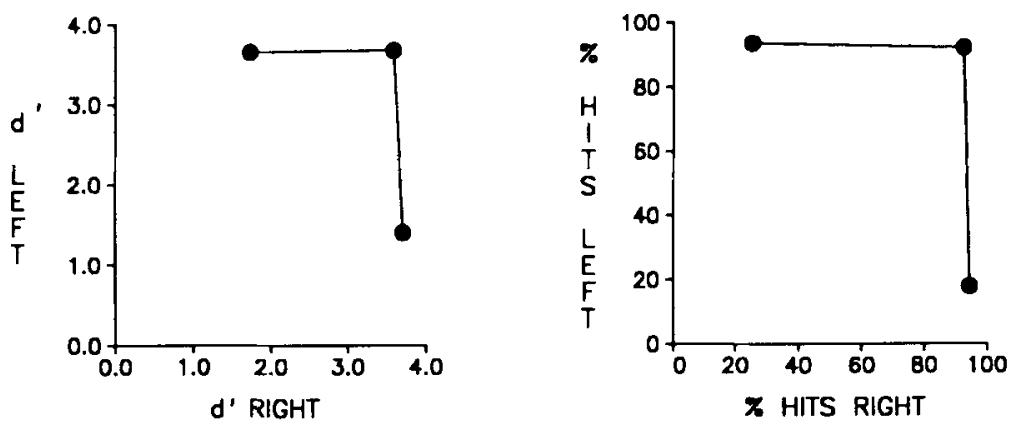

\section{Subjects}
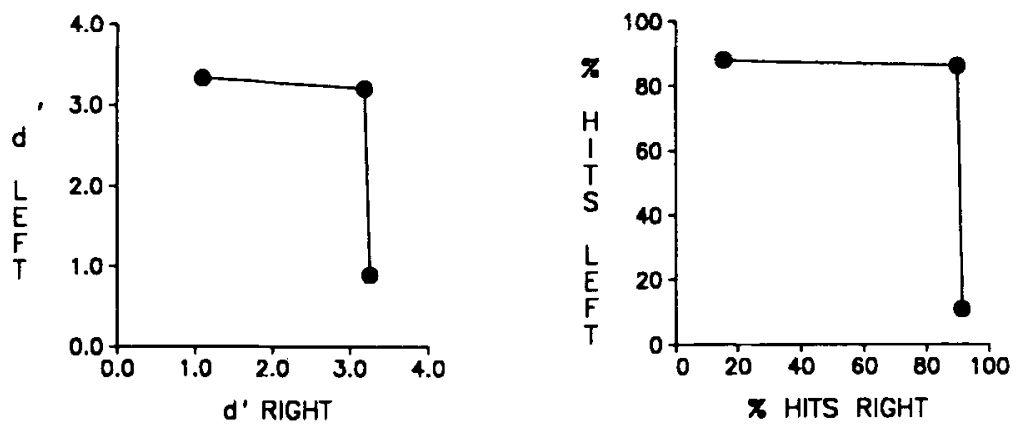

Figure 11. AOC curves for behavioral performance in Experiment 3. The plots at the top are for the 6 subjects who detected and responded to targets in all conditions; the plots at the bottom are for all subjects. Four of the 10 subjects included in the plots at bottom did not respond to stimuli for which $5 \%$ attention was to be allocated. $A$ value of zero was used for their $d^{\prime}$ scores in order to arrive at the mean values plotted. 
origin of the plot (Sperling \& Melcher, 1978; Wickens, 1984). When the data of Experiment 1 are analyzed in this way, the following measures are obtained: The AOC curves for the early sensory-evoked P110 and the anterior P200-400 waves had distance scores of 53\% and 54\%, respectively (percentage of the distance from origin to "independence point"'). ${ }^{6}$ The distance score for the occipital N180 was $26 \%$; for the parietal N165 it was $42 \%$ and for the anterior N145 it was $36 \%$. In contrast, the distance score for the occipital N350-650 was 75\%, and for the P400-800 (targets) it was 70\%. Similarly, the distance scores for $d^{\prime}$ and percent hits were $93 \%$ and $89 \%$, respectively. ${ }^{7}$ These distance scores support the conclusion of the linear regression analyses presented earlier that a dichotomy exists between the early and late ERP components. Furthermore, they provide a means of comparing the AOC curves for performance and for the ERP components; the performance curves were substantially closer to the independence point and thus more similar to the AOC curves for the long-latency ERPs.

\section{GENERAL DISCUSSION}

Systematic manipulation of the relative allocation of attention between left and right stimulus arrays produced graded amplitude changes in a number of ERP components. As more attention was allocated to the stimuli flashed in one visual field, ERPs elicited by those stimuli increased in amplitude, while ERPs to the opposite field stimuli progressively decreased. This general pattern was true for the early, sensory-evoked waves (occipital P110 and $\mathrm{N} 180$, parietal $\mathrm{N} 165$, and anterior N145), as well as the longer latency, endogenous $\mathrm{P} 400-800$ (i.e., P300) to targets. The posterior N350-650 and anterior P200-400 components also varied with attention, although this was only observed in Experiment 1 . In addition, measures of target detectability and RT showed systematic tradeoffs as a function of attentional allocation. These findings reinforce results of previous studies, in which ERPs in focused and divided attention conditions were compared, which demonstrated divided attention decrements in both sensory-evoked ERP amplitude and detection performance during visual-spatial attention (Eason, 1981; Van Voorhis \& Hillyard, 1977). These data also demonstrate the reciprocity of information processing resources that has been investigated in several previous studies concentrating on the P300 component during dual-task performance (e.g., Isreal et al., 1980; Wickens et al., 1983). The distinctive shapes of the allocation functions obtained in the present experiments, however, provide additional information about the relationships between the different classes of ERP components and perceptual processing during spatial attention.

\section{AOC Curves for Detection Performance}

Although the target-detectability measures ( $d^{\prime}$ and percent hits) did exhibit significant decrements as a function of attentional allocation, the corresponding AOC curves were suggestive of a rather efficient dual-task perfor- mance, since they lay relatively far from the origin of the graph and were nearly rectangular in shape (Navon \& Gopher, 1979; Wickens, 1984). The relatively small performance decrements going from focused $(100 \% / 0 \%)$ to divided $(75 \% / 25 \%)$ conditions may be interpreted in several ways, which are outlined below.

First, the efficient dual-task performance could indicate data limitations in the letter detection task. Norman and Bobrow (1975) defined "data limited" performance as that which is not improved by increases in resource allocation due to limits in the quality of information available in the stimulus. Thus, according to this formulation, the slow falloff for the performance scores, going from the focused to the divided condition, would indicate regions where one task was data-limited while the other was not. For example, a data limitation could account for the slow falloff in the $d^{\prime}$ AOC curve (Figure 6) if the discriminability of the briefly flashed letter arrays in a given field was limited so that the subjects' performance reached its maximal value with only a $75 \%$ attentional allocation to that field. One possible explanation for such a limit on discriminability could be the acuity limitations that occur as a function of retinal eccentricity (Eriksen \& Shultz, 1978).

On the other hand, a nearly rectangular AOC curve could also result if all of the subjects' processing resources were not fully committed during the $100 \%$ focused attention condition. Thus, when confronted with the added difficulty of a second task, the subjects would have spare resources to allocate. Indeed, it may be difficult to maintain $100 \%$ allocation to one side in tasks such as these, due to the intrinsic nature of the attentional system. Given the strong automatic orienting that takes place in response to lateralized visual stimuli, a certain amount of orienting of attention might be expected to occur to the unattended side, even under the $100 \% / 0 \%$ condition (Briand \& Klein, 1987; Jonides, 1981; Jonides \& Yantis, 1988; Müller \& Rabbitt, 1989; Posner et al., 1980).

The interpretations above assume that a single processing resource was being variably allocated to the left and right arrays. Yet another explanation for the rectangular form of the performance AOC curves would arise, however, if the left and right target-detection tasks drew upon independent "pools" of resources. For example, if the processing of left stimuli was primarily carried out by the right hemisphere and that of right stimuli was primarily carried out by the left hemisphere, a rectangular or datalimited type of AOC curve might be produced. In such a case, the resource-limited regions of these AOC curves over the $75 \% / 50 \% / 25 \%$ allocation range might simply reflect interference between two separate resource pools or the involvement of a common, partially shared resource (Navon \& Gopher, 1979; Norman \& Bobrow, 1975; Wickens, 1984).

\section{AOC Curves for ERPs}

The AOC curves for the longer latency endogenous components closely resembled those found for the performance measures. The AOC plots for the N350-650 
(Experiment 1) and target $\mathrm{P} 300$ (P400-800) components (both experiments) showed nearly rectangular curves indicative of an efficient sharing of the processing resources indexed by these ERPs during divided attention. As described above for the performance AOC curves, rectangular AOC functions could result from data limitations in the higher pattern analyses, or the effective sharing of a single dedicated resource, or perhaps the tapping of partially independent resources for the analysis of left and right stimulus arrays.

The similarity between the AOC curves for the longer latency ERP waves and performance scores suggests a close coupling between these two classes of measures in the present letter detection task. Thus, the present findings are in accord with evidence that the amplitude of the P300 wave is strongly predictive of behavioral outcome in many types of target detection tasks (see, e.g., Hoffman et al., 1985; Kramer et al., 1988; Parasuraman, Richer, \& Beatty, 1982; Squires, Hillyard, \& Lindsay, 1973), as is the latter phase of the selection negativity (Harter \& Previc, 1978). However, the rectangular form of the AOC curves for P300 (P400-800) obtained here appears to differ from what was obtained by Hoffman et al. (1985) during dual-task performance. Hoffman et al. reported that the AOC curve for P300 amplitude was linear in form when subjects allocated attention between visual letter search and dot discrimination tasks. They interpreted their findings as support for the idea that P300 amplitude indexes a limited-capacity perceptual system, whereby when resources were withdrawn from one task, they became available for utilization in a second competing task.

The P300 tradeoff in the present task, in contrast, is suggestive of rather efficient divided attention processing. One possible explanation for these differences may have to do with the degree of mutual interference produced by the concurrent tasks used in each study. Dual-task performance of two quite different tasks such as letter search and dot detection may be less compatible, thereby producing greater interference than when attention is divided between spatially separate but equivalent letter search tasks as were used here. Hence, more linear AOC plots could be obtained for dual-task than for divided attention paradigms. An additional consideration is that the stimuli used in the present study consisted of letter arrays flashed one at a time in the left or right visual field, whereas Hoffman et al. flashed the letter and dot stimuli together. In the present study, subjects may have been able to reallocate processing resources to the iconic store of the less attended side's letter arrays on a trial-by-trial basis. Thus, performance and measures of central perceptual processing such as P300 may have been higher than predicted for the lower levels of attentional allocation.

In contrast with the findings for $\mathrm{P} 300$ (P400-800) and performance, the earlier, sensory-evoked $\mathrm{P} 110$ and N145, $\mathrm{N} 165$, and $\mathrm{N} 180$ peaks displayed AOC curves with steep, approximately linear tradeoff functions in both experiments. This type of pattern implies that a single, limited resource was being shared between the two stimulus ar- rays, so that increases in attention to one side resulted in proportional decreases in the resources available for processing the opposite side. Such linear tradeoffs might also be produced, for example, if the attentional facilitation of early visual processing in one region of the visual field is coupled with a concomitant inhibition of processing in other regions. Following our previous interpretation (Mangun \& Hillyard, 1988), these early components would appear to reflect a capacity limitation in the sensory gain control over information flowing to higher visual centers. This presumed gain control mechanism may act to enhance the sensory information arising from attended as opposed to unattended location stimuli, thereby allowing relevant information to be selectively transmitted to higher systems for further analysis (Hawkins et al., 1988; Shulman \& Posner, 1988).

The distinctive AOC curves for the early rather than the late ERP components and performance measures in this task suggest that reductions in sensory signal strength need not be paralleled by proportional reductions in detection performance or associated endogenous ERP activity. Thus, as attention was increasingly withdrawn from one visual field and allocated to the other, the higher level perceptual processes were still able to extract and analyze the information from the progressively diminishing sensory signal. In other words, the higher processing stages could achieve accurate identification of the letter targets at a relatively low level of sensory gain. As a result, target-detection performance was not primarily limited by sensory input gain, but rather by limits in the ability of the higher stages to analyze or resolve the patterned features in the briefly presented, nonfoveal displays. This uncoupling of sensory gain and perceptual performance may provide an explanation for the lack of strong correlations between P110 or N180 peak amplitudes and target-detection scores in these and previous experiments (Mangun \& Hillyard, 1988).

We would predict that in tasks in which target detection depends more directly on adequate sensory input gain, such as threshold-level signal detection paradigms, or as when stimulus quality is very poor or attention must be focused on one of many simultaneously presented stimuli, performance would exhibit stronger correlations with the amplitudes of the early components of the visual eventrelated potential. In any case, the distinctive allocation functions of the early and late ERP components indicate that separate levels of attentional selection having different operating principles contributed to the ultimate detection performance in this visual-spatial attention task. Thus, the present findings fit well within the framework of multiple resource theory (see, e.g., Wickens, 1980, 1984), which distinguishes among the resources utilized at different levels of information processing.

\section{REFERENCES}

Bonnel, A. M., Possamai, C. A., \& Schmitt, M. (1987). Early modulation of visual inputs: A study of attentional strategies. Quarterly Journal of Experimental Psychology, 39A, 757-776. 
BRIAND, K. A., \& KLEIN, R. M. (1987). Is Posner's "beam" the same as Treisman's "glue"'?: On the relation between visual orienting and feature integration theory. Joumal of Experimental Psychology: Human Perception \& Performance, 13, 228-241.

Donchin, E., Karis, D., Bashore, T. R., Coles, M. G. H., GratTON, G. (1986). Cognitive psychophysiology and human information processing. In M. G. H. Coles, E. Donchin, \& S. W. Porges (Eds.), Psychophysiology (pp. 244-267). New York: Guilford Press.

Downing, C. J. (1988). Expectancy and visual-spatial attention: Effects on perceptual quality. Joumal of Experimental Psychology: Human Perception \& Performance, 14, 188-202.

EASON, R. G. (1981). Visual evoked potential correlates of early neural filtering during selective attention. Bulletin of the Psychonomic Society, 18, 203-206.

EASON, R., HARTER, M., \& WhITE, C. (1969). Effects of attention and arousal on visually evoked cortical potentials and reaction time in man. Physiology \& Behavior, 4, 283-289.

ERIKSEN, C. W. \& SChultz, D. W. (1978). Temporal factors in visual information processing: A tutorial review. In J. Requin (Ed.), Attention and performance (Vol. 7, pp. 3-23). Hillsdale, NJ: Erlbaum.

ERIKSEN, C. W., YEH, Y. Y. (1985). Allocation of attention in the visual field. Joumal of Experimental Psychology: Human Perception \& Performance, 11, 583-597.

HANSEN, J. C., HillyaRd, S. A. (1980). Endogenous brain potentials associated with selective auditory attention. Electroencephalography \& Clinical Neurophysiology, 49, 277-290.

HARTER, M. R., \& AINE, C. J. (1984). Brain mechanisms of visual selective attention. In R. Parasuraman \& D. R. Davies (Eds.), Varieties of attention (pp. 293-322). New York: Academic Press.

Harter, M. R., Aine, C. J., \&Chroeder, C. (1982). Hemispheric differences in the neural processing of stimulus location and type: Effects of selective attention on visual evoked potentials. Neuropsychologia, 20, $421-438$.

Harter, M. R., \& Previc, F. H. (1978). Size-specific information channels and selective attention: Visual evoked potentials and behavioral measures. Electroencephalography \& Clinical Neurophysiology, 45, 628-640.

Hawkins, H. L., Shafto, M. G., \& Richardon, K. (1988). Effects of target luminance and cue validity on the latency of visual detection. Perception \& Psychophysics, 44, 484-492.

Heinze, H. J., Luck, S. J., Mangun, G. R., Hillyard, S. A. (in press). Visual event-related potentials index focussed attention within bilateral stimulus arrays: I. Evidence for early selection. Electroencephalography \& Clinical Neurophysiology.

Herdman, C. M., \& Friedman, A. (1985). Multiple resources in divided attention: A cross-modal test of the independence of hemispheric resources. Journal of Experimental Psychology: Human Perception \& Performance, 11, 40-49.

Hillyard, S. A., Mangun, G. R. (1987). Sensory gating as a physiological mechanism for visual selective attention. In R. Johnson, Jr., R. Parasuraman, \& J. W. Rohrbaugh (Eds.), Current trends in eventrelated brain potentials (EEG Suppl. 40, pp. 61-67). New York Elsevier.

Hilly ARD, S. A., \& Münte, T. F. (1984). Selective attention to color and location: An analysis with event-related brain potentials. Perception \& Psychophysics, 36, 185-198.

Hillyard, S. A., \& Picton, T. W. (1987). Electrophysiology of cog nition. In V. B. Mountcastle (Ed.), Handbook of physiology: Sec. 1 . The nervous system: Vol. 5. Higher brain functions (Part 2, pp. 519584). Baltimore: American Physiological Society.

Hillyard, S. A., Simpson, G. V., Woods, D. L., Van Voorhis, S. \& MÜNTE, T. F. (1984). Event-related brain potentials and selective attention to different modalities. In F. Reinoso-Suarez \& C. AjmoneMarsen (Eds.), Cortical integration: Basic, archicortical, and cortical association levels of neural integration (pp. 395-414). New York Raven Press

Hoffman, J. E., Houck, M. R., MacMillan, F. W., Simons, R. F., \& OATMAN, L. C. (1985). Event-related potentials elicited by automatic targets: A dual task analysis. Journal of Experimental Psychology: Human Perception \& Performance, 11, 50-61

IsREa L, J. B., Wickens, C. D., Chesney, G. L., \& Donchin, E.
(1980). The event-related brain potential as an index of display monitoring workload. Human Factors, 22, 212-224.

JENNINGS, J. R., \& WOOD, C. C. (1976). The epsilon-adjustment procedure for repeated-measures analyses of variance. Psychophysiology, 13, $277-278$.

JoNIDES, J. (1981). Voluntary versus automatic control over the mind's eye's movement. In J. Long \& A. Baddeley (Eds.), Attention and performance (Vol. 9, pp. 187-203). Hillsdale, NJ: Erlbaum.

JoNIDES, J., \& YANTIS, S. (1988). Uniqueness of abrupt visual onset in capturing attention. Perception \& Psychophysics, 43, 346-354.

KinCHLA, R. A. (1980). The measurement of attention. In R. S. Nickerson (Ed.), Attention and performance (Vol. 8, pp. 213-217). Hillsdale, NJ: Erlbaum.

Kramer, A. F., Sirevaag, E. J., * Hughes, P. R. (1988). Effects of foveal task load on visual-spatial attention: Event-related brain potentials and performance. Psychophysiology, 25, 512-531

Kramer, A. F., \&TRAYER, D. (1987). P300 operating characteristics: Performance/ERP analysis of dual-task demands and attention. In M. Kutas \& B. Renault (Eds.), Proceedings of the Fourth International Conference on Cognitive Neurosciences (pp. 110-112). Paris.

Kramer, A. F. , Stra Yer, D. (1988). Assessing the development of automatic processing: An application of dual-task and event-related brain potential methodologies. Biological Psychology, 26, 231-267.

Mangun, G. R., Hansen, J. C., Hillyard, S. A. (1987). The spatial orienting of attention: Sensory facilitation or response bias? In R. Johnson, Jr., R. Parasuraman, \& J. W. Rohrbaugh (Eds.), Current trends in event-related brain potentials (EEG Suppl. 40, pp. 118124). New York: Elsevier.

MAngun, G. R., Hillyard, S. A. (1987). The spatial allocation of visual attention as indexed by event-related brain potentials. Human Factors, 29, 195-212

Mangun, G. R., Hillyard, S. A. (1988). Spatial gradients of visual attention: Behavioral and electrophysiological evidence. Electroencephalography \& Clinical Neurophysiology, 70, 417-428.

Mangun, G. R., \& Hillyard, S. A. (1990). Electrophysiological studies of visual selective attention in humans. In A. Scheibel \& A. Wechsler (Eds.), The neurobiological foundations of higher cognitive function. New York: Guilford.

Moran, J., Desimone, R. (1985). Selective attention gates visual processing in the extrastriate cortex. Science, 229, 782-784.

Mountcastle, V. B., Motter, B. C., Steinmetz, M. A., \& SesTOKAS, A. K. (1987). Common and differential effects of attentive fixation on the excitability of parietal and prestriate (V4) cortical visual neurons in the macaque monkey. Journal of Neuroscience, 7 , 2239-2255

Müller, H. J., \& Findlay, J. M. (1987). Sensitivity and criterion effects in the spatial cuing of visual attention. Perception \& Psychophysics, 42, 383-399.

MülleR, H. J., \& RABbitT, P. M. A. (1989). Reflexive and voluntary orienting of visual attention: Time course of activation and resistance to interruption. Joumal of Experimental Psychology: Human Perception \& Performance, 15, 315-330.

NAvoN, D., \& Gopher, D. (1979). On the economy of the humanprocessing system. Psychological Review, 86, 214-255.

Neville, H. J., \& LAwSON, D. (1987). Attention to central and peripheral visual space in a movement detection task: An event-related potential and behavioral study. I. Normal hearing adults. Brain Research, 405, 253-267.

Norman, D. A., Bobrow, D. G. (1975). On data-limited and resource-limited processes. Cognitive Psychology, 7, 44-64.

Parasuraman, R. (1985). Event-related brain potentials and intermodal divided attention. In R. Swezey (Ed.), Proceedings of the Human Factors Society 29th Annual Meeting (pp. 971-975). Baltimore, MD.

Parasuraman, R., Richer, F., \& Beatty, J. (1982). Detection and recognition: Concurrent processes in perception. Perception \& Psychophysics, 31, 1-12.

Posner, M. I., SNyder, C. R. R., \& Davidson, B. J. (1980). Attention and the detection of signals. Journal of Experimental Psychology: General, 109, 160-174.

Previc, F. H., \& Harter, M. R. (1982). Electrophysiological and be- 
havioral indicants of selective attention to multifeature gratings. Perception \& Psychophysics, 32, 465-472.

Prinzmetal, W., Presti, D. E., \& Posner, M. I. (1986). Does attention affect visual feature integration? Journal of Experimental Psychology: Human Perception \& Performance, 12, 361-369.

Pritchard, W. S. (1981). Psychophysiology of P300. Psychological Bulletin, 89, 506-540.

Rugg, M. D., Milner, A. D., Lines, C. R., \& Phalp, R. (1987). Modulation of visual event-related potentials by spatial and non-spatial visual selective attention. Neuropsychologia, 25, 85-89.

SHAW, M. L. (1984). Division of attention among spatial locations: A fundamental difference between detection of letters and detection of luminance increments. In H. Bouma \& D. G. Bouwhuis (Eds.), Attention and performance: Vol. 10. Control of language processes (pp. 109-121). Hillsdale, NJ: Erlbaum.

Shulman, G. L., PoSNER, M. I. (1988). Relating sensitivity and criterion effects to the internal mechanisms of visual spatial attention (ONR Tech. Rep. 88-2). Arlington, VA: Psychological Sciences Division, Office of Naval Research.

SperLing, G. (1984). A unified theory of attention and signal detection. In R. Parasuraman \& D. R. Davies (Eds.), Varieties of attention (pp. 103-181). New York: Academic Press.

SPERLING, G., \& MELCHER, M. J. (1978). Visual search, visual attention, and the attention operating characteristic. In J. Requin (Ed.), Attention and performance (Vol. 7, pp. 675-686). Hillsdale, NJ: Erlbaum.

Spitzer, H., Desimone, R., \& Moran, J. (1988). Increased attention enhances both behavioral and neuronal performance. Science, $\mathbf{2 4 0}$, 338-340.

Squires, K. C., Hillyard, S. A., \& Lindsay, P. H. (1973). Vertex potentials evoked during auditory signal detection: Relation to decision criteria. Perception \& Psychophysics, 14, 265-272.

VAN Voorhis, S., \&illyard, S. A. (1977). Visual evoked potentials and selective attention to points in space. Perception \& Psychophysics, 22, 54-62.

WICKENS, C. D. (1980). The structure of attentional resources. In R. Nickerson (Ed.), Attention and performance (Vol. 8, pp. 239-257). Hillsdale, NJ: Erlbaum.

Wickens, C. D. (1984). Processing resources in attention. In R. Parasuraman \& D. R. Davies (Eds.), Varieties of attention (pp. 63-102). New York: Academic Press

Wickens, C. D., Kramer, A. F., Vanasse, L., \& Donchin, E. (1983). Performance of concurrent tasks: A psychological analysis of the reciprocity of information-processing resources. Science, 221, 10801082.

Wijers, A. A., Mulder, G., Okita, T., Mulder, L. J. M., \& SCHEFFERS, M. K. (1989). Attention to color: An analysis of selection, controlled search, and motor activation using event-related potentials. Psychophysiology, 26, 89-109.

\section{NOTES}

1. The mean rejection rate for eye movements across visual field of stimulus, attention condition, and subjects was $10.8 \% \pm 0.6 \%$. There were no significant differences in rejection rate as a function of attention condition $[F(4,60)=1.3, p>.30]$.

2. ANOVA Factor B (attention condition) represents the proportion of attention allocated to a given visual field. Thus, the main effect of attention collapses over the left and right visual field stimuli.

3. Only three of the five ERP traces are overlapped in Figure 2 to reduce the clutter associated with overlapping five waveforms (see Figure 3).

4. Regressions of $d^{\prime}$ versus occipital N350-650 between subjects had correlation coefficients that ranged from -.44 to -.55 : Values were regressed across visual fields separately for each attention condition. Correlation coefficients and significance levels $[F(1,30)]$ for $100 \%, 75 \%$, $50 \%$, and $25 \%$ conditions were, respectively, $r=-.55, p<.001$; $r=-.54, p<.002 ; r=-.45, p<.01$; and $r=-.47, p<.001$. When regressed for each attention condition separately, subjects with higher $d^{\prime}$ scores tended to have smaller N350-650 components, despite the fact that, in general, across attention conditions the N350-650 was larger for conditions of greater attentional allocation (where $d^{\prime}$ was correspondingly higher).

5. We thank Jeff Miller for pointing out the difficulty in plotting the discrimination accuracy scores in the $0 \%$ allocation as zero in Experiments 1 and 2.

6. Distance scores were obtained from the AOC curves of Figures 6 and 7 through calculation of the distance from the origin to the independence point at which a line between the two would intersect the AOC curve.

7. The distance scores for performance measures in Experiment 1 were computed with $(0,0)$ as the origin of the plot. The basic finding that the distance scores for performance tend to be large and more similar to the distance score for P400-800 and N350-650 would not be altered for Experiment 1 even if the origin were defined by the performance during $75 \%$ allocation. The distance scores for $d^{\prime}$ and percent hits when calculated in this latter manner would be $70 \%$ and $80 \%$, respectively. However, as indicated by the results of Experiment 3, a more accurate value is probably somewhere between $70 \%$ and $93 \%$ for $d^{\prime}$, since these values indicate the lower and upper limits calculated from the most conservative and liberal values for the origin, respectively.

(Manuscript received April 10, 1989; revision accepted for publication January 4, 1990.) 